\title{
Review \\ Opto-Electronic Oscillators for Micro- and Millimeter Wave Signal Generation
}

\author{
Mehmet Alp Ilgaz * and Bostjan Batagelj \\ Faculty of Electrical Engineering, University of Ljubljana, 1000 Ljubljana, Slovenia; bostjan.batagelj@fe.uni-lj.si \\ * Correspondence: mehmet.ilgaz@fe.uni-lj.si
}

check for

updates

Citation: Ilgaz, M.A.; Batagelj, B.

Opto-Electronic Oscillators for Micro-

and Millimeter Wave Signal

Generation. Electronics 2021, 10, 857.

https: / / doi.org/10.3390/

electronics 10070857

Academic Editor: Geok Ing Ng

Received: 3 March 2021

Accepted: 1 April 2021

Published: 3 April 2021

Publisher's Note: MDPI stays neutral with regard to jurisdictional claims in published maps and institutional affiliations.

Copyright: (c) 2021 by the authors. Licensee MDPI, Basel, Switzerland. This article is an open access article distributed under the terms and conditions of the Creative Commons Attribution (CC BY) license (https:// creativecommons.org/licenses/by/ $4.0 /)$.

\begin{abstract}
High-frequency signal oscillators are devices needed for a variety of scientific disciplines. One of their fundamental requirements is low phase noise in the micro- and millimeter wave ranges. The opto-electronic oscillator (OEO) is a good candidate for this, as it is capable of generating a signal with very low phase noise in the micro- and millimeter wave ranges. The OEO consists of an optical resonator with electrical feedback components. The optical components form a delay line, which has the advantage that the phase noise is independent of the oscillator's frequency. Furthermore, by using a long delay line, the phase noise characteristics of the oscillator are improved. This makes it possible to widen the range of possible OEO applications. In this paper we have reviewed the state of the art for OEOs and micro- and millimeter wave signal generation as well as new developments for OEOs and the use of OEOs in a variety of applications. In addition, a possible implementation of a centralized OEO signal distribution as a local oscillator for a 5G radio access network (RAN) is demonstrated.
\end{abstract}

Keywords: opto-electronic oscillator; phase noise; microwave signal; millimeter wave signal; 5G radio access network; long-term stability; multimode operation; wideband OEO; integrated OEO

\section{Introduction}

High-precision signal oscillators are needed in a variety of fields such as satellite communications, optical communications, radar applications, radio-over-fiber communications, etc. [1]. In its most basic form, an oscillator consists of a resonator and a feedback component. When the Barkhausen conditions are satisfied, the oscillator starts generating the fundamental oscillation signal. An opto-electronic oscillator (OEO) is one of the most popular types of oscillators for generating micro- and millimeter wave signals [2,3]. The OEO has a number of optical components such as a laser diode [4,5], an optical fiber [6] and a photodiode [7]. The electrical components including an electrical bandpass filter and an electrical amplifier are used to complete the feedback loop. The laser of the OEO can be modulated directly, or it can use external modulation with an electro-optic modulator such as a Mach Zehnder modulator (MZM) [8] or an electro-absorption modulator [9]. A typical externally modulated OEO is shown in Figure 1.

Currently, $-163 \mathrm{dBc} / \mathrm{Hz}$ at a $6 \mathrm{kHz}$ offset from the carrier for an operating frequency of $10 \mathrm{GHz}$ [10] is the lowest phase noise achieved so far. Different types of configurations for the OEO have already been presented in the literature. The dual-loop and multi-loop configurations [11-14], coupled OEO [15-18], injection-locked OEO [19-22], OEO with quality multiplier [23], and OEO with feedback loop [24] are some of the well-known configurations. Moreover, optical solutions are possible by adding components such as optical filters [25-27] and optical amplifiers [28,29] or by adjusting the optical link to achieve an optical gain [30]. These are already used to improve the stabilization of the OEO. Since an OEO consisting of such bulky components is very large, some methods to reduce the size of the oscillator device have already been reported. There are several solutions such as using a whispering-gallery-mode resonator (WGMR) [31-34], a ring 
resonator [35,36], or an electro-absorption modulated laser [37] that decrease the size of the OEO. In 2017, a fully integrated OEO was reported in the literature by J. Tang et al. [38,39]. In addition, a theoretical and experimental study of the characteristics of an injection-locked OEO was presented and published in several journals [40-44]. Recently, a W-band OEO was introduced by G.K.M. Hasanuzzaman et al. [45]. The OEO provided a phase noise characteristic of $-101 \mathrm{dBc} / \mathrm{Hz}$ at a $10 \mathrm{kHz}$ offset from the $94.5 \mathrm{GHz}$ carrier. On the other hand, an opto-electronic parametric oscillator [46] was reported in 2020.

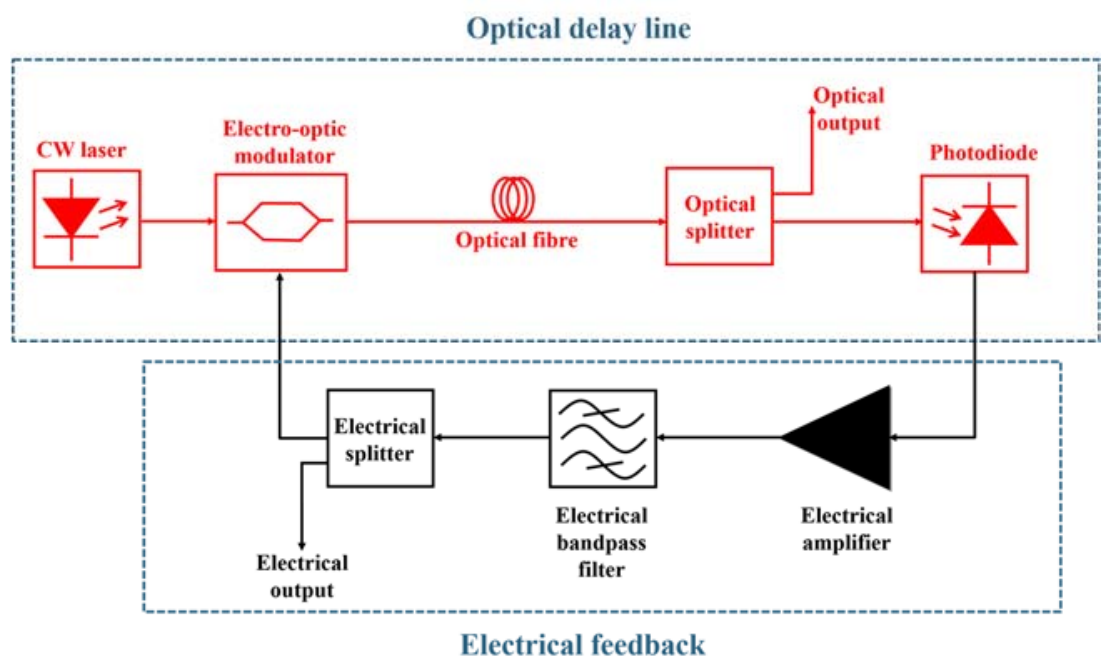

Figure 1. Single-loop opto-electronic oscillator (OEO) with electrical components.

There are some more recent developments in the use of OEOs in various applications. One example of this is terahertz (THz) photonic signal generation using an OEO [47-49]. Another possible application of an OEO is to use it as a local oscillator (LO) in the central office of a 5G radio access network (RAN) [50-52]. The single-loop OEO can be combined with an optical fiber path selector to measure the free spectral range (FSR) and side-mode suppression ratio (SMSR) of the OEO for different lengths of the optical delay line [53]. There are other applications of OEOs such as an acoustic sensor [54], low-power radio frequency (RF) signal detection [55], phase-locked loops [56-58], parity time-symmetric OEO [59,60], silicon micro-ring-based OEO [61] and linear frequency-modulated waveform generation [62], etc.

Long-term stability and side modes (multimode operation) are the main challenges affecting the stabilization of an OEO. The OEO uses an optical fiber that is mainly affected by the temperature variations in the environment. This leads to fluctuations in the oscillation frequency over time, which is referred to as the frequency drift (in other words, long-term stability). On the other hand, electrical bandpass filters have bandwidth limitations in the micro- and millimeter wave ranges. Electric bandpass filters are used in the oscillator loop to destroy the side modes in the RF spectrum and determine the main mode of the oscillation. Due to the bandwidth limitation of the filter, the side modes are not completely filtered out, and they can therefore be seen in the RF spectrum. The ratio between the fundamental mode and the spurious side modes is called SMSR.

The short-term stability (i.e., phase noise) is mainly based on the length of the delay line of the OEO. The OEO can use a long delay line to achieve the lowest possible phase noise. However, using a long delay line boosts the power of the side modes because the FSR becomes lower, and the side modes are more difficult to filter out due to the bandwidth limitation of the electrical filter. For instance, the use of a 1-km fiber has an FSR of $200 \mathrm{kHz}$, while a $15 \mathrm{~km}$ fiber has an FSR of $13.4 \mathrm{kHz}$. The relationship between SMSR and phase noise performance of the OEO at different optical lengths is shown in Figure 2. 


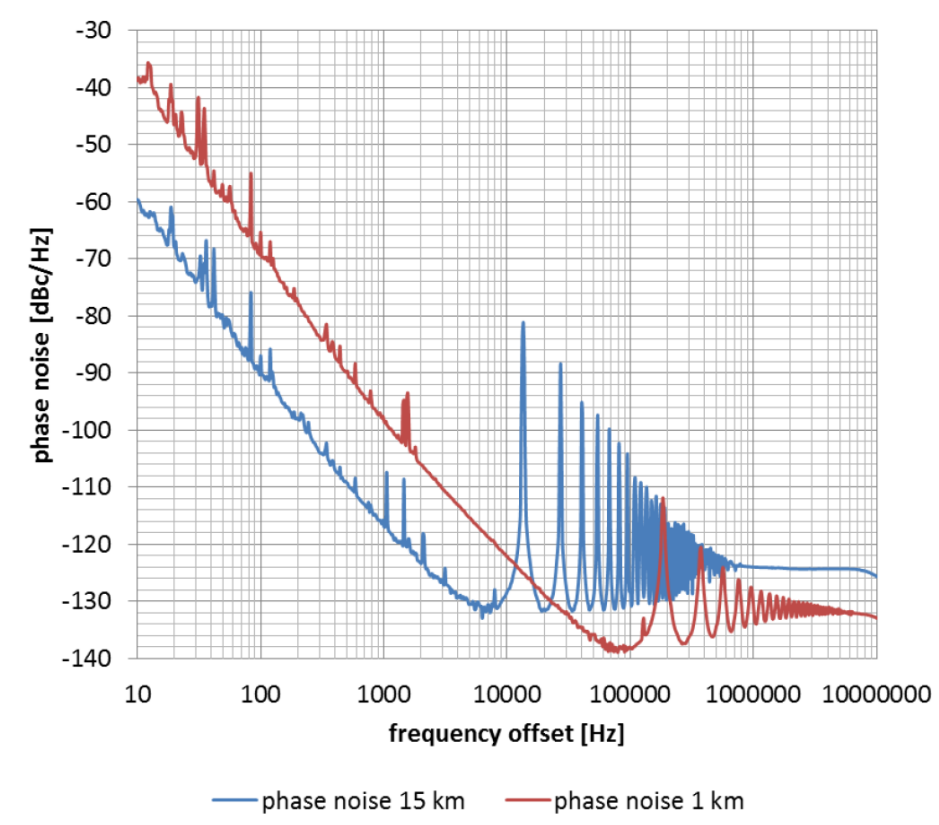

Figure 2. Comparison of phase noise and side-mode suppression ratio (SMSR) performance of OEO with $1 \mathrm{~km}$ and $15 \mathrm{~km}$ delay line length [1]. Reprinted with permission from ref. [1]. Copyright 2015 IEEE.

As can be seen from the experimental results in Figure 2, there is a tradeoff between the short-term stability and multimode operation of the OEO. The $1 \mathrm{~km} \mathrm{OEO} \mathrm{has} \mathrm{about} \mathrm{a} 30 \mathrm{~dB}$ improvement performance in the SMSR, but the $15 \mathrm{~km}$ OEO has a significant improvement in phase noise, which is about $20 \mathrm{~dB}$ at $1 \mathrm{kHz}$ and $10 \mathrm{kHz}$ offsets from the carrier.

In this paper, recent advances in OEO configurations are presented, using new results to improve the stability of short-term, long-term and multimode operation. It also highlights new areas of science, technology and engineering where the OEO can be applied.

\section{Current Progress of the Common Topologies of the OEO}

In this section, the paper focuses on recent advances in the development of OEOs and the main challenges that they face: multimode operation, as well as short-term and long-term stability. In the first subsection, the paper focuses on multimode operation and short-term stability, with long-term stability following this subsection.

\subsection{Progress of the OEO toward Lower SMSR and Phase Noise}

As mentioned earlier, one of the general challenges associated with OEO design is multimode operation. Since an electrical bandpass filter has bandwidth limitations, some optical solutions have been proposed. One of the most popular solutions is to form more than one optical delay line. These dual or multi-loop OEOs have seen widespread use for more than 20 years to eliminate multimode operation [63]. The typical configuration of a dual-loop OEO is shown in Figure 3. In this configuration, one loop is used as a long cavity, while the other behaves as a short cavity. This is achieved by using short and long fibers in different loops. One of the recent advances in the dual-loop OEO is the use of multicore fibers and the self-polarization-stabilization technique [64]. Conventionally, two or more single-mode fibers (SMFs) are used to form a dual- or multi-loop configuration. In this novel approach, the combination of cores in a multicore fiber is used to form a short and a long cavity [64]. With this novel approach, an SMSR of $61 \mathrm{~dB}$ was achieved for a microwave OEO oscillating at $7.8 \mathrm{GHz}$. Another recent approach is parity symmetry of the OEO with a dual-loop configuration [65]. The parity symmetry is achieved by using two optical carriers with different optical powers. Parity symmetry provides additional gain for the main mode. With the combination of parity symmetry and a dual loop, a $60.71 \mathrm{~dB}$ SMSR was achieved for a $10 \mathrm{GHz}$ central frequency. 


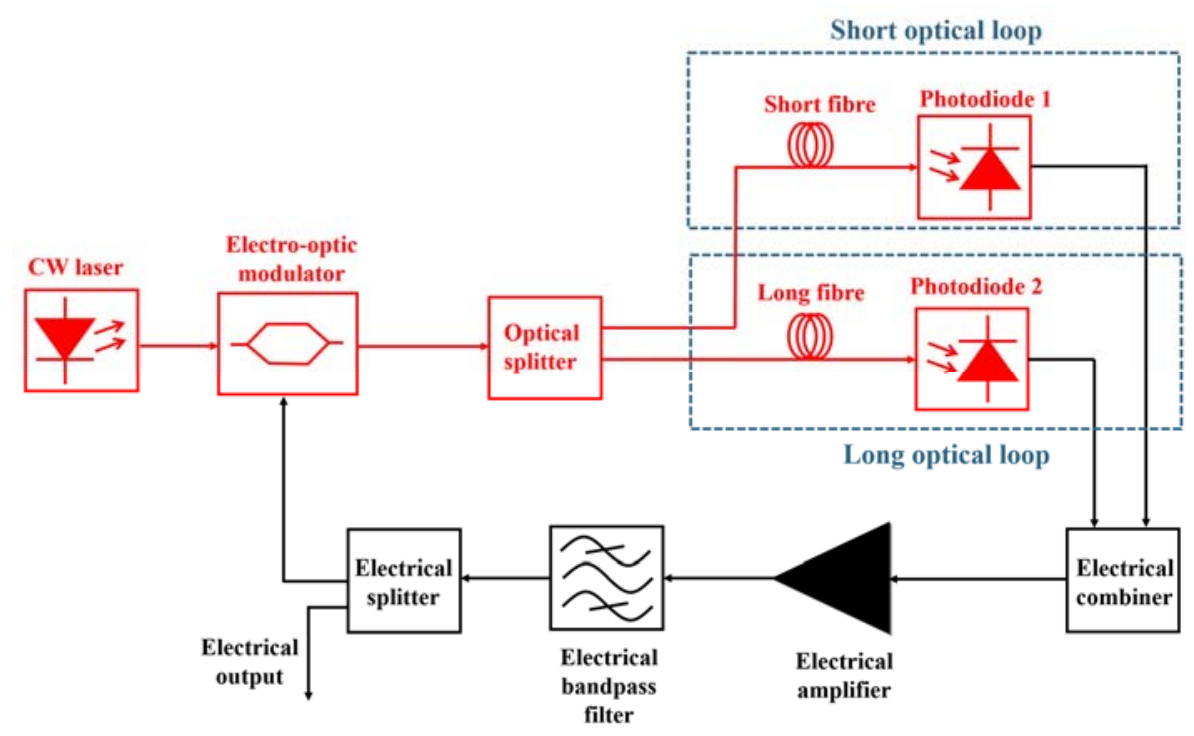

Figure 3. Typical dual-loop configuration of an OEO.

An injection-locked OEO is another configuration to improve the SMSR performance of the OEO. It was first proposed in $2005[63,66]$. The typical configuration of an injectionlocked OEO is shown in Figure 4. In the typical configuration of the OEO, it consists of two oscillator blocks. One of them is classified as the master OEO and other as the slave OEO [63]. This approach is used to suppress the spurious side modes and at the same time maintain the quality factor (Q-factor) of the OEO [63]. The slave OEO is used to suppress the spurious side modes as it employs a short fiber, while the master OEO employs a long fiber to keep the high Q-factor. In reference [67], a tunable, dual-loop, injection-locked OEO was presented. The OEO was tunable from $11.1 \mathrm{GHz}$ to $12.1 \mathrm{GHz}$, and the spurious side modes were suppressed below $-115 \mathrm{dBc} / \mathrm{Hz}$ [67]. Another approach was to form a microwave frequency divider based on the injection-locked OEO [68]. In this implementation, the $10 \mathrm{GHz}$ free-running OEO was injected with a $20 \mathrm{GHz}$ microwave signal. A single-sideband (SSB) phase noise of $-130 \mathrm{dBc} / \mathrm{Hz}$ at a $10 \mathrm{kHz}$ offset was achieved. In Reference [69], an injection-locked OEO based on stimulated Brillouin scattering (SBS) is described. This approach provided a frequency tunability up to $40 \mathrm{GHz}$ with an SMSR of $60 \mathrm{~dB}$ and an SSB noise of $-116 \mathrm{dBc} / \mathrm{Hz}$ at a $10 \mathrm{~Hz}$ offset.

The coupled OEO, introduced in 1997 [63,70], is another type of commonly used OEO configuration to improve SMSR. In this configuration, the OEO consists of an optical loop and an opto-electronic loop coupled via an electro-optic modulator [63]. The coupled OEO is used to improve the phase noise characteristics and the SMSR. The typical configuration of a coupled OEO is shown in Figure 5. An example of a recent development in the coupled OEO was the synthesis of a $90 \mathrm{GHz}$ signal using a $30 \mathrm{GHz}$ coupled OEO [71]. The $90 \mathrm{GHz}$ signal was obtained by biasing the MZM to the third harmonic. An SSB phase noise of $-104 \mathrm{dBc} / \mathrm{Hz}$ at a $1 \mathrm{kHz}$ offset from the $90 \mathrm{GHz}$ carrier was achieved in this configuration [71]. On the other hand, a novel, coupled OEO with an erbium-doped fiber (EDF) has been proposed [72]. The novel configuration allows a large spatial hole burning (SHB) using the unpumped EDF to improve the SMSR and the phase noise. An SMSR of more than $72.5 \mathrm{~dB}$ was achieved wherein the SSB phase noise was $-123.6 \mathrm{dBc} / \mathrm{Hz}$ at a $10 \mathrm{kHz}$ offset from the $10 \mathrm{GHz}$ carrier signal. 


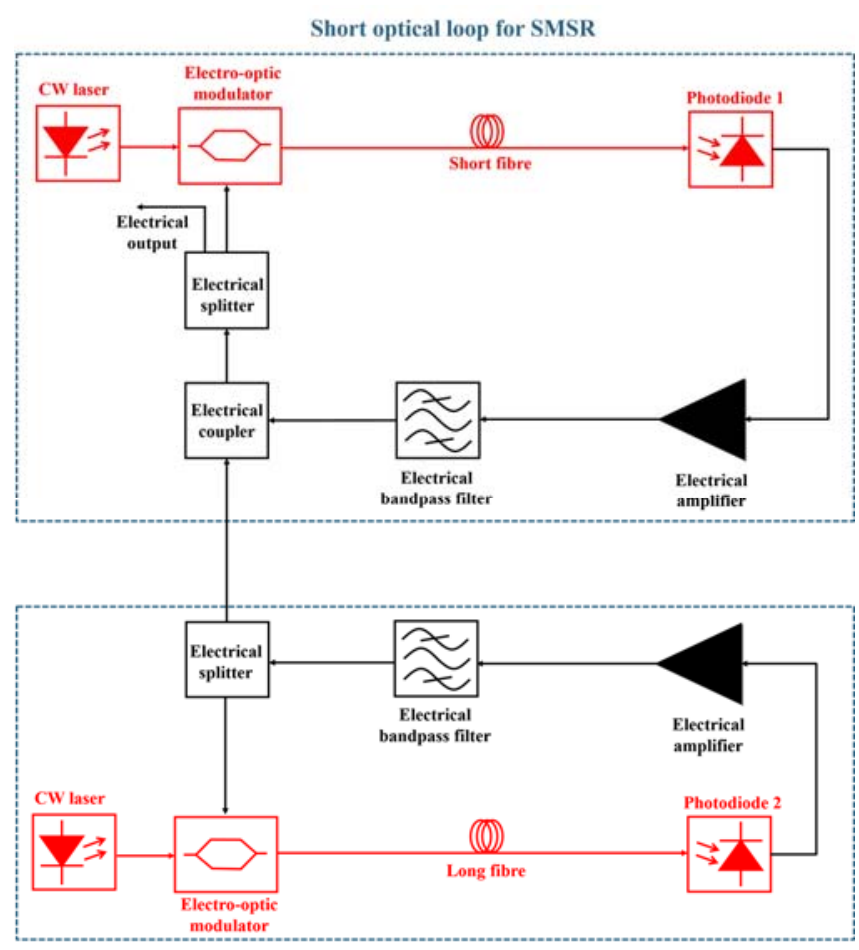

Long optical loop for supplying high-Q resonator

Figure 4. Typical injection-locked OEO.

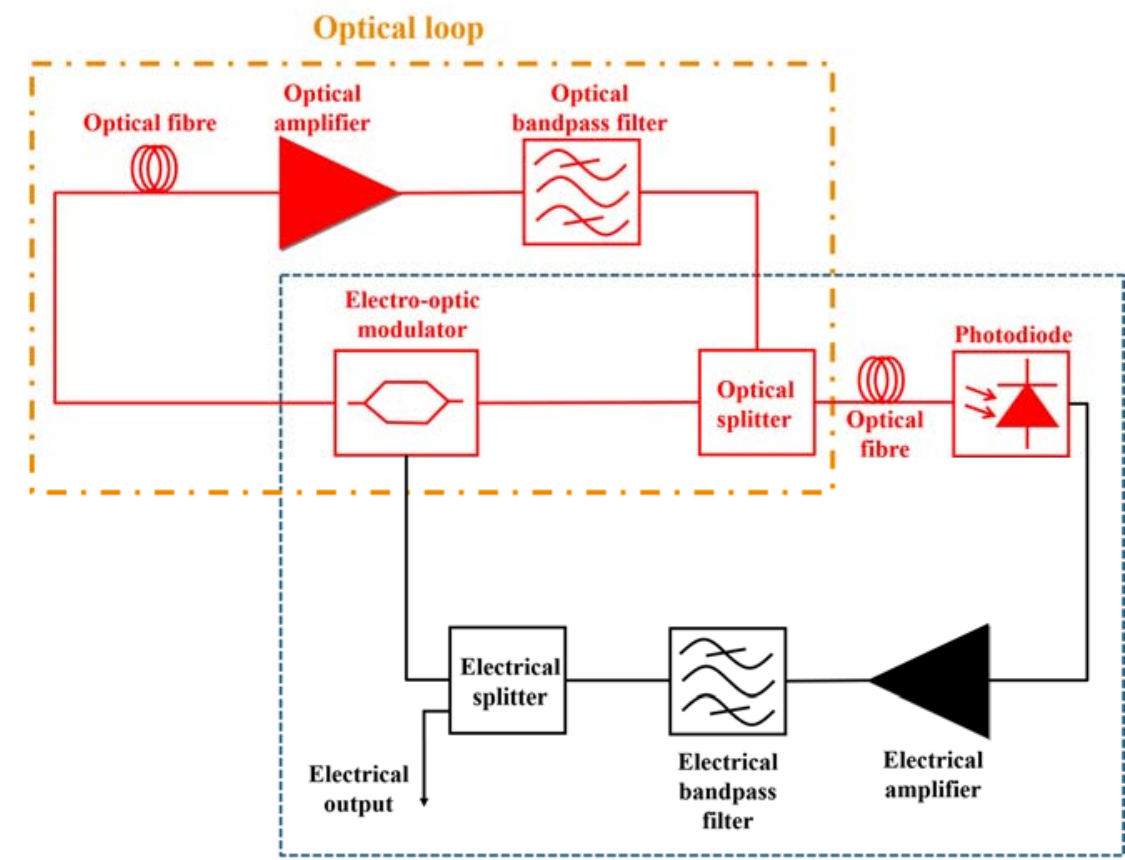

Opto-electronic oscillator feedback loop

Figure 5. Typical configuration of a coupled OEO.

In addition to the typical solutions listed above, there are other novel solutions to improve the phase noise and/or the SMSR characteristics of the OEO. For a millimeterwave OEO, a high-quality opto-electronic filter was proposed, e.g., a Q-factor of 30,000 at a central frequency of $29.99 \mathrm{GHz}$ [73]. This resulted in an $83 \mathrm{~dB}$ SMSR and a $-113 \mathrm{dBc} / \mathrm{Hz}$ SSB phase noise at a $10 \mathrm{kHz}$ offset. A cascaded microwave filter was presented in [49]. In this configuration, the cascaded filter configuration was implemented with a single passband filter having an opto-electronic filter. With this approach, an SMSR of $125 \mathrm{~dB}$ 
and an SSB phase noise of $-103 \mathrm{dBc} / \mathrm{Hz}$ for a $10 \mathrm{kHz}$ offset at the $17.33 \mathrm{GHz}$ carrier were achieved. The linewidth of the laser can affect the phase-noise performance of the OEO. A narrowband microcavity laser with a physical side length of $16 \mu \mathrm{m}$ is used for the microwave signal generation in the loop of the OEO [74]. An SSB phase noise of $-116 \mathrm{dBc} / \mathrm{Hz}$ was achieved for a $10 \mathrm{kHz}$ offset from the carrier microwave signal. The microwave signal can be tuned between $1.85 \mathrm{GHz}$ and $10.24 \mathrm{GHz}$ thanks to a tunable optical bandpass filter.

\subsection{Progress of the OEO toward Better Long-Term Stability}

Long-term stability is another important characteristic of the OEO. The electrical bandpass filter and the optical fiber are major components of the OEO that are temperaturedependent [75]. For the frequency drift of a non-temperature-stabilized OEO operating at a $10 \mathrm{GHz}$ central frequency, $8 \mathrm{ppm} / \mathrm{K}$ was measured [75]. One of the useful approaches is the temperature stabilization of the optical fiber and the electrical bandpass filter of the OEO loop [75]. With this solution, $0.1 \mathrm{ppm} / \mathrm{K}$ was achieved. In 2016, Luka Bogataj et al. brought another approach, i.e., the OEO with a feedback control loop [24,76]. The configuration of the feedback control loop is shown in Figure 6.

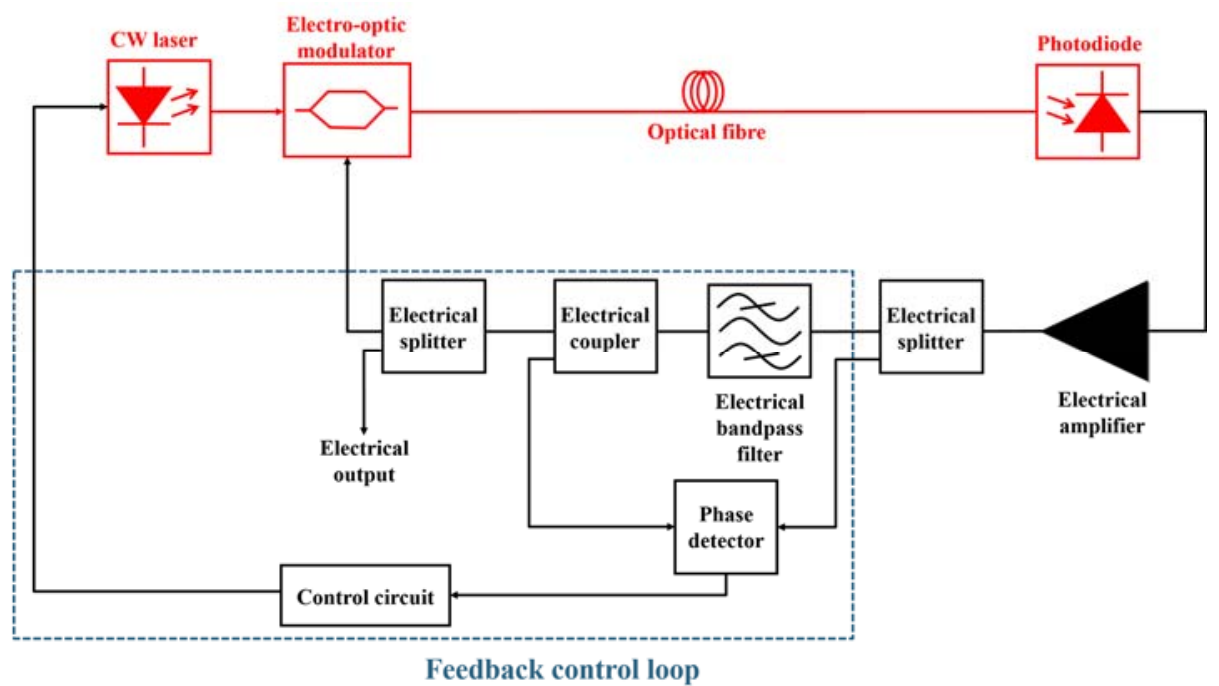

Figure 6. OEO with a feedback-control loop.

In the feedback control loop, the frequency discriminator controls the temperature of the laser by measuring the refractive index of the optical fiber. A proportional-integral (PI) controller is used to control the temperature of the laser. Using the feedback control loop, a frequency drift of $0.05 \mathrm{ppm} / \mathrm{K}$ was achieved for a single-loop OEO operating at $3 \mathrm{GHz}$. In 2017, the optical delay stabilization system (ODSS) was introduced [77] for active fiber delay stabilization at a different wavelength than used in the oscillator loop. The outstanding result of a $0.02 \mathrm{ppm} / \mathrm{K}$ frequency drift was achieved for a $3 \mathrm{GHz}$ OEO. However, the frequency of the oscillator can be increased, but this does not affect the stability result because the stabilization is performed at an independent wavelength.

Phase-locked loops (PLLs) are alternative solutions that are widely used in practice to improve the long-term stability of the OEO signal. In this case, the OEO signal is locked by the PLL signal [78]. The typical configuration of an OEO with a PLL is shown in Figure 7.

For an OEO with a PLL configuration, a stable reference signal is required to improve the long-term stability. Wen-Hung Tseng proposed another approach to improving the long-term stability that involves a fiber-delay monitoring mechanism [79]. This mechanism monitors the fiber delay using an injected probe signal. A thermal drift of $10^{-7} \mathrm{~s}$ was achieved after 4000 seconds with the monitoring mechanism. 


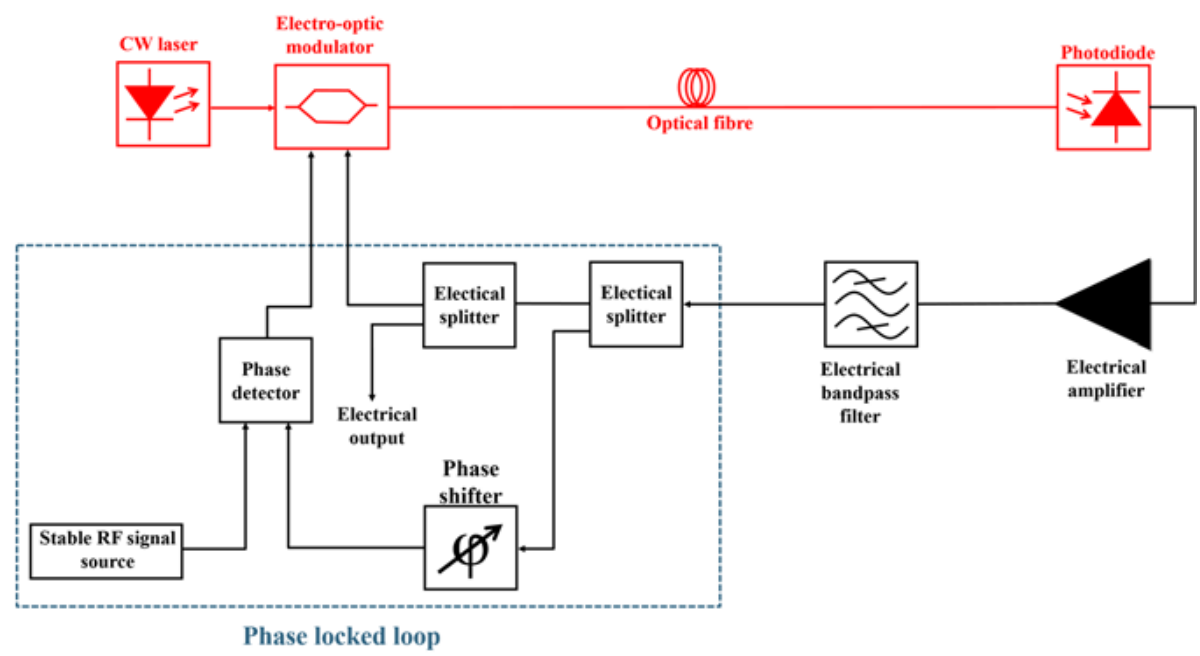

Figure 7. Typical configuration of an OEO with a PLL configuration.

\subsection{General Overview}

In this section of the paper, we would like to compare the performance of different configurations of the $\mathrm{OEO}$ in multimode operation: short-term stability (i.e., phase noise) and long-term stability. In the first table, different configurations of the OEO are described by comparing the SMSR and the phase noise.

For Table 1, OEOs with the same or similar frequency were selected (except for the OEO with a high quality opto-electronic filter) to allow a more accurate and scientific comparison of the phase noise in different solutions. However, in theory, the OEO has a stable phase-noise characteristic that is independent of the operating frequency [1], so higher frequencies can be used for the comparison. In the SMSR comparison, the optical delay line length and the bandwidth of the electrical and/or optical filter are more important for the comparison. When considering the phase noise, the injection-locked OEO achieves the best performance among the other solutions. On the other hand, the cascaded micro-wave photonic filter solution achieved a better result in terms of the SMSR.

Table 1. Comparison of the SMSR and the phase noise of the current results for various advanced configurations of the OEO.

\begin{tabular}{|c|c|c|c|c|}
\hline Configuration & $\begin{array}{l}\text { Optical Delay Line } \\
\text { Length }\end{array}$ & Central Frequency & SMSR & $\begin{array}{l}\text { Phase Noise (@10 kHz } \\
\text { offset from the carrier) }\end{array}$ \\
\hline Dual-loop OEO [64] & $\begin{array}{l}\text { 7-core fiber } \\
(105 \mathrm{~m})\end{array}$ & From $3.5 \mathrm{GHz}$ to $17.1 \mathrm{GHz}$ & $61 \mathrm{~dB}$ & $-100 \mathrm{dBc} / \mathrm{Hz}$ \\
\hline Injection-locked OEO [68] & $\begin{array}{l}\text { Single-mode fibers } \\
(1 \mathrm{~km} \text { and } 0.7 \mathrm{~km})\end{array}$ & $10 \mathrm{GHz}$ & $\mathrm{N} / \mathrm{A}$ & $-130 \mathrm{dBc} / \mathrm{Hz}$ \\
\hline Coupled OEO [72] & $\begin{array}{l}\text { Erbium-doped fiber } \\
\qquad(4 \mathrm{~m})\end{array}$ & $10 \mathrm{GHz}$ & $72.5 \mathrm{~dB}$ & $-123.6 \mathrm{dBc} / \mathrm{Hz}$ \\
\hline $\begin{array}{l}\text { OEO with high-quality } \\
\text { opto-electronic filter [73] }\end{array}$ & $\begin{array}{l}\text { Dispersion-shifted } \\
\text { fiber }(3 \mathrm{~km})\end{array}$ & $29.99 \mathrm{GHz}$ & $83 \mathrm{~dB}$ & $-113 \mathrm{dBc} / \mathrm{Hz}$ \\
\hline $\begin{array}{l}\text { Cascading microwave } \\
\text { photonic filter [49] }\end{array}$ & $\begin{array}{l}\text { Single-mode fibers } \\
(2 \mathrm{~km} \text { and } 0.2 \mathrm{~km})\end{array}$ & $17.33 \mathrm{GHz}$ & $125 \mathrm{~dB}$ & $-103 \mathrm{dBc} / \mathrm{Hz}$ \\
\hline $\begin{array}{l}\text { Narrowband microwave laser } \\
\text { with dual-loop OEO [74] }\end{array}$ & $\begin{array}{l}\text { Single-mode fibers } \\
(2.5 \mathrm{~km} \text { and } 3 \mathrm{~km})\end{array}$ & From $1.85 \mathrm{GHz}$ to $10.24 \mathrm{GHz}$ & $55 \mathrm{~dB}$ & $-116 \mathrm{dBc} / \mathrm{Hz}$ \\
\hline
\end{tabular}

In Table 2, different solutions are compared to evaluate the performance of the OEO in terms of long-term stability and phase noise. 
Table 2. Comparison of the different techniques to achieve long-term stability in the OEO.

\begin{tabular}{ccccc}
\hline Configuration & $\begin{array}{c}\text { Optical Delay Line } \\
\text { Length }\end{array}$ & Central Frequency & Long-term Stability & $\begin{array}{c}\text { Phase Noise (@10 kHz } \\
\text { offset from the carrier) }\end{array}$ \\
\hline Temperature stabilization [75] & $\mathrm{N} / \mathrm{A}$ & $10 \mathrm{GHz}$ & $0.1 \mathrm{ppm} / \mathrm{K}$ & $-143 \mathrm{dBc} / \mathrm{Hz}$ \\
\hline $\begin{array}{c}\text { OEO with feedback-control } \\
\text { loop [76] }\end{array}$ & $15 \mathrm{~km}$ & $3 \mathrm{GHz}$ & $0.05 \mathrm{ppm} / \mathrm{K}$ & $<-130 \mathrm{dBc} / \mathrm{Hz}$ \\
\hline $\begin{array}{c}\text { Optical delay stabilization } \\
\text { system [77] }\end{array}$ & $3 \mathrm{~km}$ & $3 \mathrm{GHz}$ & $0.02 \mathrm{ppm} / \mathrm{K}$ & $-123 \mathrm{dBc} / \mathrm{Hz}$ \\
\hline OEO with PLL [78] & $\begin{array}{c}500 \mathrm{~m} \\
\text { (Dispersion deduced } \\
\text { fiber) }\end{array}$ & $3 \mathrm{GHz}$ & $\begin{array}{c}6.98 \times 10^{-14} \\
\text { (average time of } 1000 \mathrm{~s})\end{array}$ & $<-100 \mathrm{dBc} / \mathrm{Hz}$ \\
\hline
\end{tabular}

The optical delay line system showed good performance in terms of long-term and short-term stability. The phase-noise performance could be improved by using a longer optical fiber. An OEO with a PLL does not have good phase noise performance because a short delay line is used. However, a classic solution such as temperature stabilization has good phase noise performance and short-term stability.

\section{Recent Development of the OEO's Application}

In this section we present and detail some recent advances in the application of OEOs in different fields as well as some new developments such as integrated OEOs and the wideband tunable OEO.

\subsection{Wideband Tunable Frequency Generation}

The conventional OEO has a narrowband tunability, which is a few $\mathrm{MHz}$ due to the bandwidth limitation of the electrical bandpass filter. To improve the tunability of the OEO, tunable microwave resonators or microwave photonic filters have been proposed [61]. They can provide tunability from hundreds of $\mathrm{MHz}$ up to tens of GHz. In 2010, W. Li published the first research paper for a wideband tunable OEO [80]. In 2017, a wideband tunable frequency generator based on a dispersion compensation fiber OEO was proposed that had a tuning range of 3-42 GHz [81]. The SSB phase noise was lower than $-110 \mathrm{dBc} / \mathrm{Hz}$ at a $10 \mathrm{kHz}$ offset from the carrier for the whole tuning range (span of about $39 \mathrm{GHz}$ ). A microwave photonic filter was used for frequency tuning, while the dispersion compensation fiber was used to compensate for the chromatic dispersion of the single-mode fiber. In 2019, a wideband frequency generator based on frequency division without a bandpass filter, but biasing the Mach-Zehnder Modulator (MZM) at the minimum transmission point, was introduced [82]. The wideband signal from $6 \mathrm{GHz}$ to $10 \mathrm{GHz}$ (or $10 \mathrm{GHz}$ to $18 \mathrm{GHz}$ ) was obtained depending on the input signal. A phase noise improvement of $5.71 \mathrm{~dB}$ was achieved at the output signal [82]. A micro-ring resonator (MRR) is another possible solution to bring wideband tunability to the OEO configuration [83]. Wideband frequency generation between 0 and $20 \mathrm{GHz}$ was achieved using an OEO with a MRR, wherein the SSB phase noise of $-95 \mathrm{dBc} / \mathrm{Hz}$ was measured at a $10 \mathrm{kHz}$ offset from the $12.23 \mathrm{GHz}$ carrier frequency [83]. The configuration of the OEO with the MRR is shown in Figure 8. 


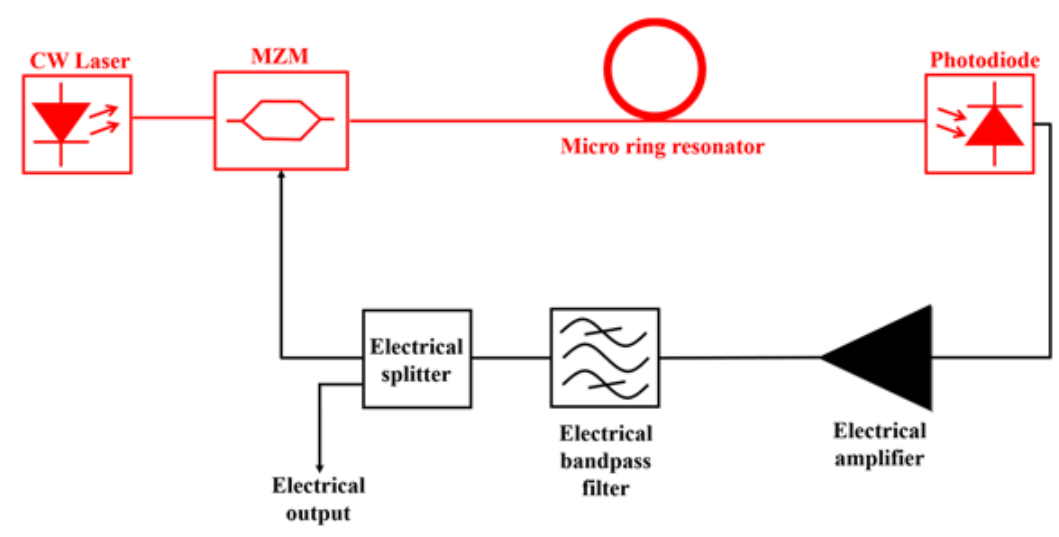

Figure 8. Simple configuration of an OEO with a micro-ring resonator (MRR).

\subsection{Photonic Integrated Chip}

The traditional OEO uses an optical fiber to form the optical delay line. This makes the OEO very large and in some cases, bulky because it contains additional components for the improvement of short-term and long-term stabilization, multimode operation, etc. (an additional delay line, additional optical and/or electrical devices, etc.). To reduce the size of the OEO, a compact OEO was proposed. In the compact OEO, the optical fiber was replaced by a whispering-gallery-mode resonator (WGMR) to reduce the size of the OEO [31-33].

The fully integrated OEO based on an InP substrate was first presented by J. Tang et al. at the Microwave Photonics Conference 2017 [38,84]. All the components were assembled in a photonic integrated chip (PIC). An optical waveguide in a spiral shape was used as an optical resonator. When a microwave frequency was generated with such an integrated $\mathrm{OEO}$, one of the main handicaps was the length of the delay line. Due to the small size of the spiral-shaped delay line, which was a few centimeters, the Q-factor of the OEO was very low, and thus the phase noise characteristics were worse than those of a non-integrated OEO. Therefore, for the integrated OEO, an SSB phase noise of $-91 \mathrm{dBc} / \mathrm{Hz}$ at a $1-\mathrm{MHz}$ offset from the $7.3 \mathrm{GHz}$ carrier was obtained [38]. The integrated OEO and its tunability and short-term performance are given in Figure 9.
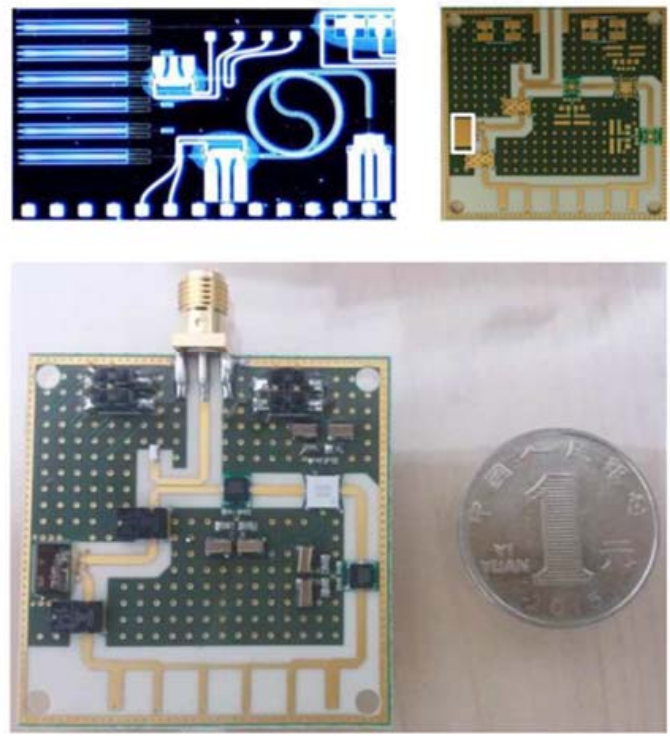
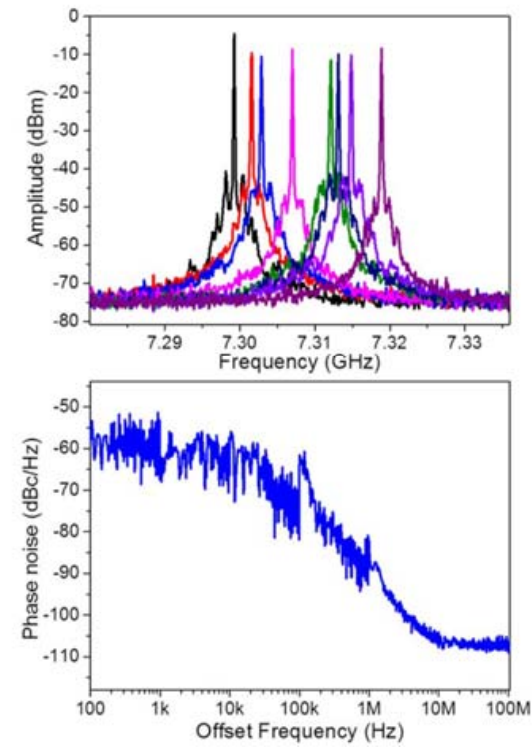

Figure 9. The integrated OEO. The frequency tunability of the OEO is around $20 \mathrm{MHz}$, with a central oscillation frequency of $7.3 \mathrm{GHz}$ [38]. Reprinted with permission from Reference [38]. Copyright 2017 IEEE. 
In addition to the integrated $\mathrm{OEO}$ on the InP substrate, an integrated $\mathrm{OEO}$ based on a silicon substrate was introduced to the literature by W. Zhang and J. Yao in 2018 [85]. A highspeed phase modulator, a tunable micro-disk resonator and a high-speed photodetector were integrated on the silicon-substrate chip. The proposed silicon photonic OEO was tunable in the frequency range between $3 \mathrm{GHz}$ and $8 \mathrm{GHz}$. The measured SSB phase noise was $-81 \mathrm{dBc} / \mathrm{Hz}$ at a $10 \mathrm{kHz}$ offset from the $4.74 \mathrm{GHz} \mathrm{RF}$ carrier signal. On the other hand, a photonic and electronic hybrid OEO was presented in 2019 [86]. In this configuration, the OEO consisted of photonic and electronic chips that were fabricated separately. An SSB phase noise of $-103 \mathrm{dBc} / \mathrm{Hz}$ at a $100 \mathrm{kHz}$ offset from the carrier was measured.

As can be clearly seen from the SSB phase noise measurements of the integrated OEO [84-86], although the integrated OEOs provide the opportunity to reduce the size and enable mass production of the OEO in the chip, they unfortunately have poor short-term stability in the microwave range. However, due to their small size, the long-term stability of the OEO can be easily improved by temperature stabilization of the chip.

\subsection{Optical Signal Distribution for the 5G Radio Access Network}

The next-generation $5 \mathrm{G}$ radio access network (RAN) has certain requirements to improve bit rate and spectral efficiency [87]. It is expected that millimeter wave bands will be used to meet these requirements [88]. The current 4G-RAN technology uses an electrical local oscillator (LO) in each base station to perform the frequency up-conversion and down-conversion of the data signal. Unfortunately, the phase-noise performance is degraded when they are used for the millimeter-wave signal range. The centralized oscillator's signal distribution was reported in the literature from several sources [89-92]. For example, in [93], we proposed the use of an OEO as a LO in a 5G RAN fronthaul. The centralized oscillator signal was distributed to the base stations without the need for electro-optical and opto-electronic conversion. Radio over fiber [94-96] is proposed as an efficient and sophisticated solution to distribute the centralized OEO signal. The idea is shown in Figure 10. The OEO signal is distributed from the central office to the base station through an optical distribution network (ODN). The data signals and the OEO signal can be transmitted over the same fiber using a dense wavelength-division-multiplexing (DWDM) approach. This approach has the advantage of keeping the ODN infrastructure simple, as well as the base station, because the LO is no longer required. Since the LOs would need to be temperature stabilized to provide a stable clock signal, it is more cost-effective to only develop one well-stabilized oscillator in the central office and distribute its signal to the base stations. In addition, the proposal has the advantage that the total number of oscillators in the whole fronthaul system is reduced. This would have a positive impact on the energy savings of the complex system if the number of oscillators was reduced.

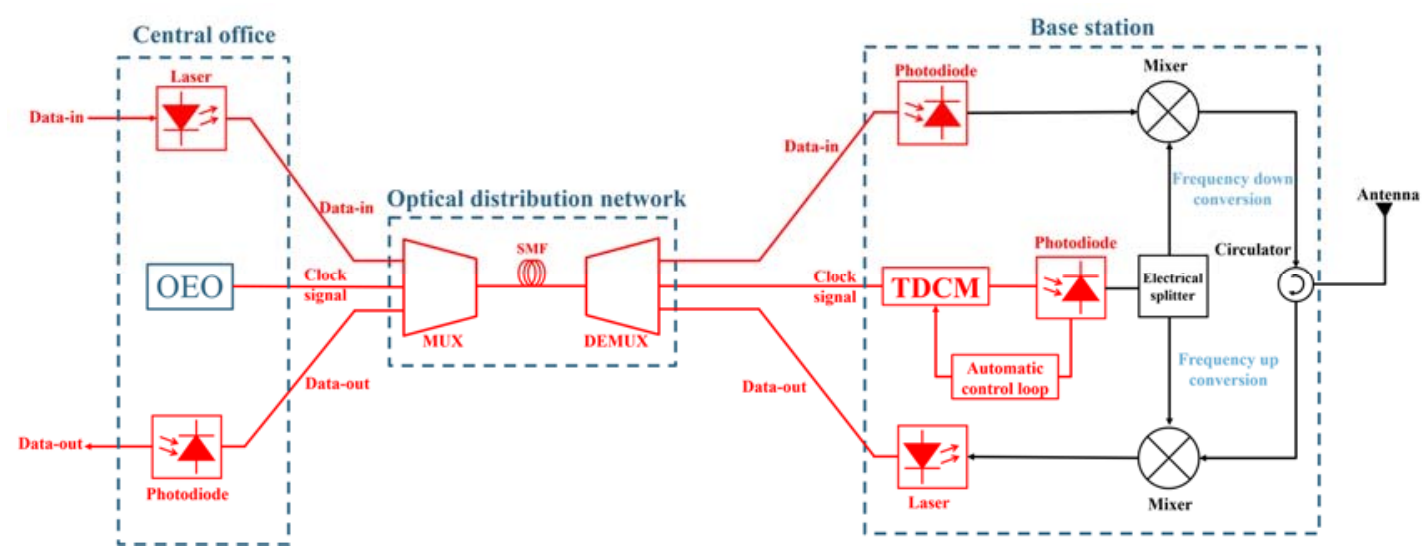

Figure 10. Use of an $\mathrm{OEO}$ as a local oscillator (LO) for a 5G radio access network (RAN) fronthaul. Reprinted from Reference [93]. 
On the other hand, the optical signal distribution of the OEO via an optical fiber presents some challenges. One of the main challenges is the power penalty due to chromatic dispersion [97]. The $C$ band is widely used in optical communications because of its advantages such as a low optical loss $(0.2 \mathrm{~dB} / \mathrm{km})$, but chromatic dispersion is very dominant in this band, ranging between approximately 16 and $17 \mathrm{ps} / \mathrm{nm} / \mathrm{km}$. Intensitymodulated links are negatively affected by the power penalty due to chromatic dispersion. Therefore, we proposed to use the tunable dispersion-compensation module (TDCM) in each base-station [93], which is shown in Figure 10. The TDCM is a device based on Bragg gratings that provides a way to compensate for the chromatic dispersion in the $\mathrm{C}$ band with respect to the actual fiber length. To test the performance of the optical signal distribution, we employed the experimental setup shown in Figure 11.

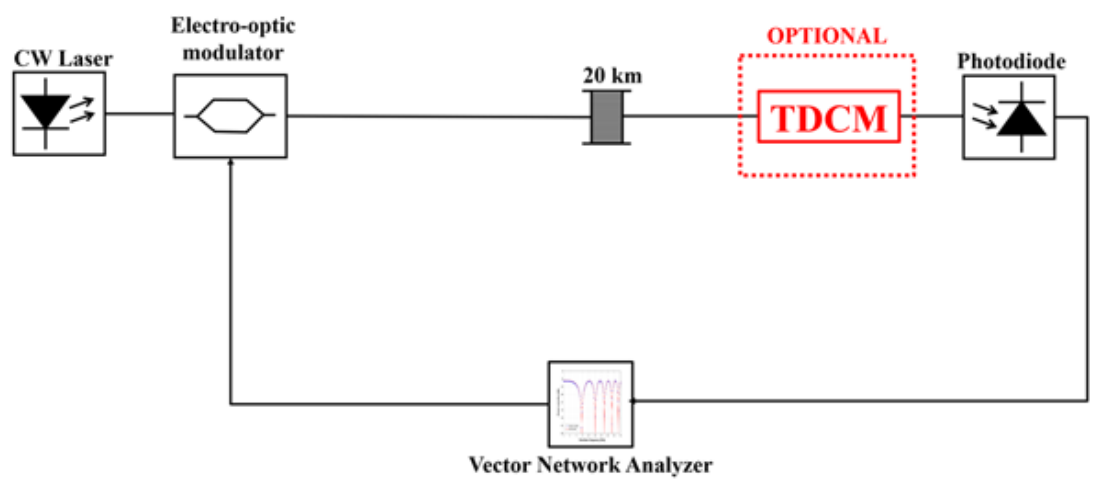

Figure 11. Experimental setup for dispersion penalty measurements with and without tunable dispersion-compensation module (TDCM).

For the experiment, we set up an optical delay line in combination with a vector network analyzer (VNA). This configuration provided the ability to apply a wideband RF signal to the optical delay line to track the full spectrum of the dispersion penalty. When the OEO was used instead of the described experimental setup, we only had the opportunity to investigate a single frequency. Therefore, we could obtain limited experimental data relevant to the dispersion penalty. The VNA provided the RF signal with a range of about $45 \mathrm{GHz}$. The results for the power penalty with and without the TDCM are shown in Figure 12.

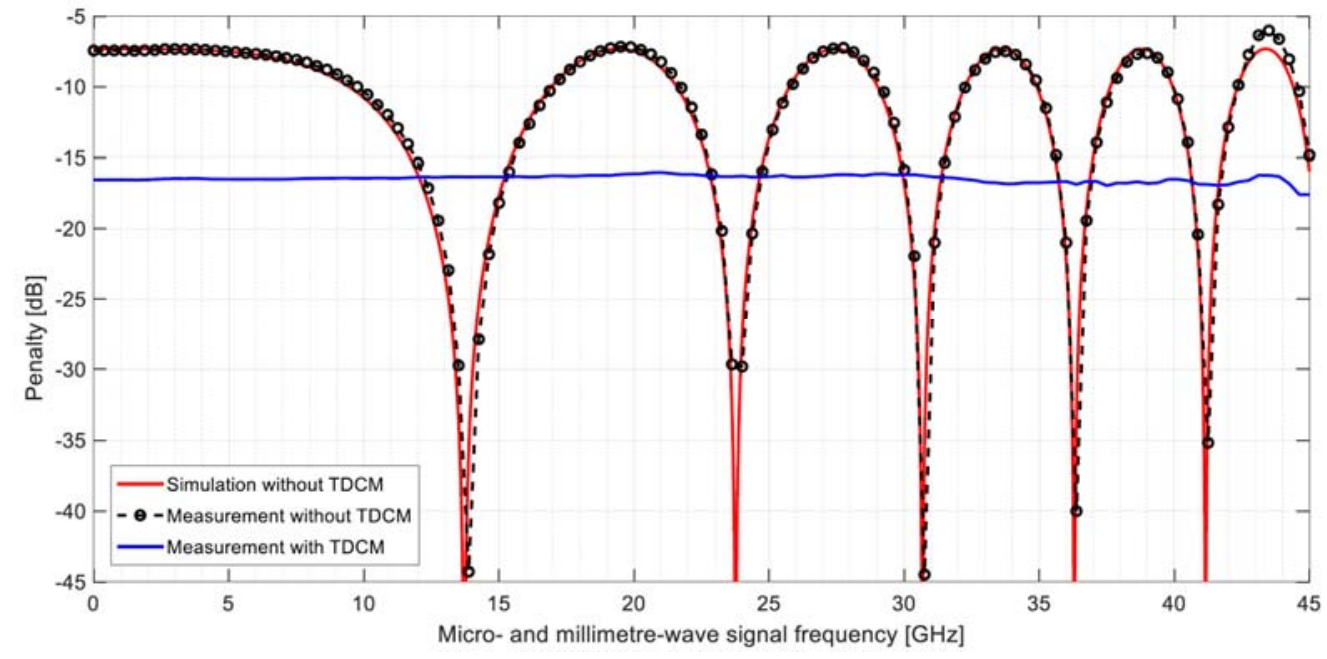

Figure 12. Power-penalty measurements from $10 \mathrm{MHz}$ to $45 \mathrm{GHz}$ over a 20-km optical fiber. Reprinted from Reference [93]. 
The results show that the TDCM can be used in any base station to compensate for chromatic dispersion in the $\mathrm{C}$ band. In other words, to avoid the power penalty of the OEO signal distribution over the ODN, the TDCM can be used at each base station. The only challenge associated with the proposal is that the TDCM requires knowledge of the exact optical length. This challenge can be solved by using a proportional-integral-derivative (PID) controller so that the TDCM can be automatically tuned by comparing the maximum RF power seen in the RF spectrum. On the other hand, there are other possible options, such as using the 1310-nm wavelength or special fibers such as a dispersion-shifted fiber (DSF). However, the use of the 1310-nm wavelength has some disadvantages such as larger optical losses compared to the $C$ band, and the optical nonlinearities are larger in this band. In addition, DSF requires modification of the infrastructure, which might not be a cost-effective and feasible approach for a RAN.

\subsection{Application for SMSR, FSR and Phase Noise Measurements}

As mentioned several times in the text, one of the main challenges associated with the OEO is multimode operation. There are some analytical approaches to calculating the SMSR [98,99]. These analytical approaches are challenging and require some system values. We have developed an application of the OEO based on the single-loop OEO with an optical fiber path selector published in 2020 [100]. The application allows rapid measurements of the SMSR, FSR and phase noise of the OEO for different optical lengths. In addition, various electrical bandpass filters can be tested to find the optimum one for the OEO. The application is shown in Figure 13.

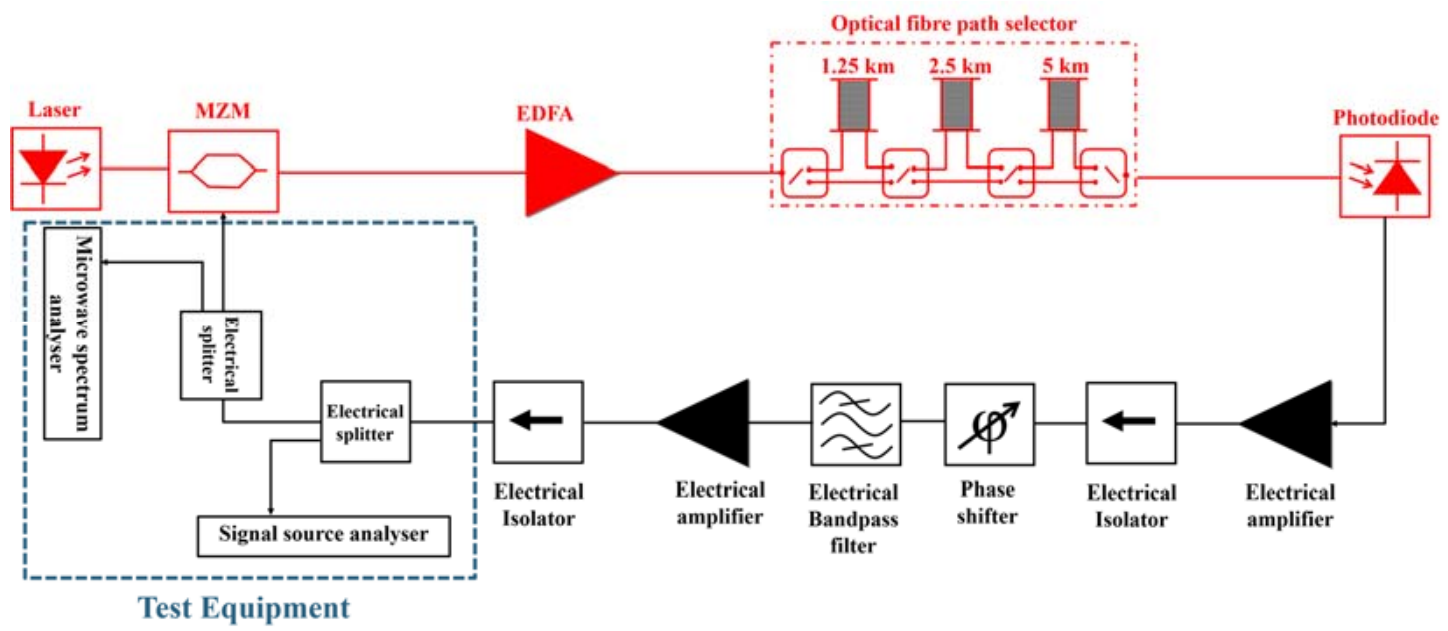

Figure 13. OEO application to measure the phase noise, SMSR and free spectral range (FSR) of the electrical bandpass filters at different optical fiber lengths. Reprinted from Reference [100].

In the configuration shown in Figure 13, a spectrum analyzer (SA) is used to verify that the Barkhausan conditions are satisfied, and a signal source analyzer (SSA) is operated to measure the phase noise, FSR and SMSR. The proposed application has the advantage of verifying, measuring and testing the various electrical bandpass filters in different optical delay lines to find the optimum one. In this application, the optical lengths are changed without the requirement to exchange the optical connectors due to the optical path selector's capability to switch between different fiber spools. Figure 14 is a photograph of the proposed application setup, while Table 3 shows the experimental results of the OEO around $9.63 \mathrm{GHz}$, where the different optical lengths are formed. 


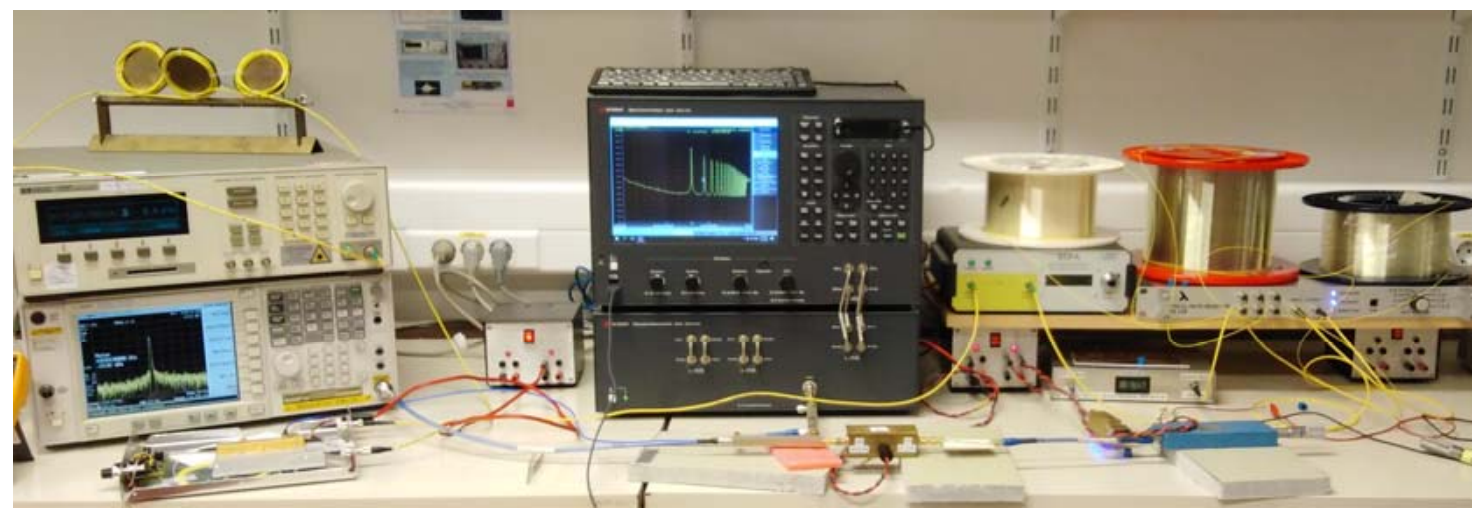

Figure 14. Photograph of the proposed application of the OEO combined with the optical fiber path selector.

Table 3. FSR, SMSR and phase noise measurements of the single-loop OEO for different optical lengths [100].

\begin{tabular}{ccccc}
\hline $\begin{array}{c}\text { Fiber Length } \\
(\mathbf{k m})\end{array}$ & $\begin{array}{c}\text { FSR } \\
(\mathbf{k H z})\end{array}$ & $\begin{array}{c}\text { SMSR } \\
\mathbf{( d B )}\end{array}$ & $\begin{array}{c}\text { Phase Noise @1 kHz } \\
\text { Offset } \\
\mathbf{( d B c / H z})\end{array}$ & $\begin{array}{c}\text { Phase Noise @10 } \\
\mathbf{k H z} \text { Offset } \\
\mathbf{( d B c / H z})\end{array}$ \\
\hline 1.25 & 158.5 & 78.1 & -73.8 & -120.7 \\
2.50 & 79.3 & 71.1 & -80.6 & -123.3 \\
5.00 & 40.2 & 62.5 & -100.9 & -123.3 \\
7.50 & 27.2 & 39.9 & -104.7 & -125.0 \\
\hline
\end{tabular}

According to the results in Table 3, the tradeoff between the phase noise and the SMSR is clearly seen when the length of the optical delay line is alternated. This application can be used to test various electrical bandpass filters in the OEO loop to find the optimum filter in terms of phase noise and SMSR. Also, the optimum optical delay line can be determined with the use of this application. In addition, with the proposed application, the phase noise result of the OEO can be obtained with the SSA. For instance, in Figure 15, the phase noise performance of an $\mathrm{OEO}$ with a length of $7.5 \mathrm{~km}$ is presented.

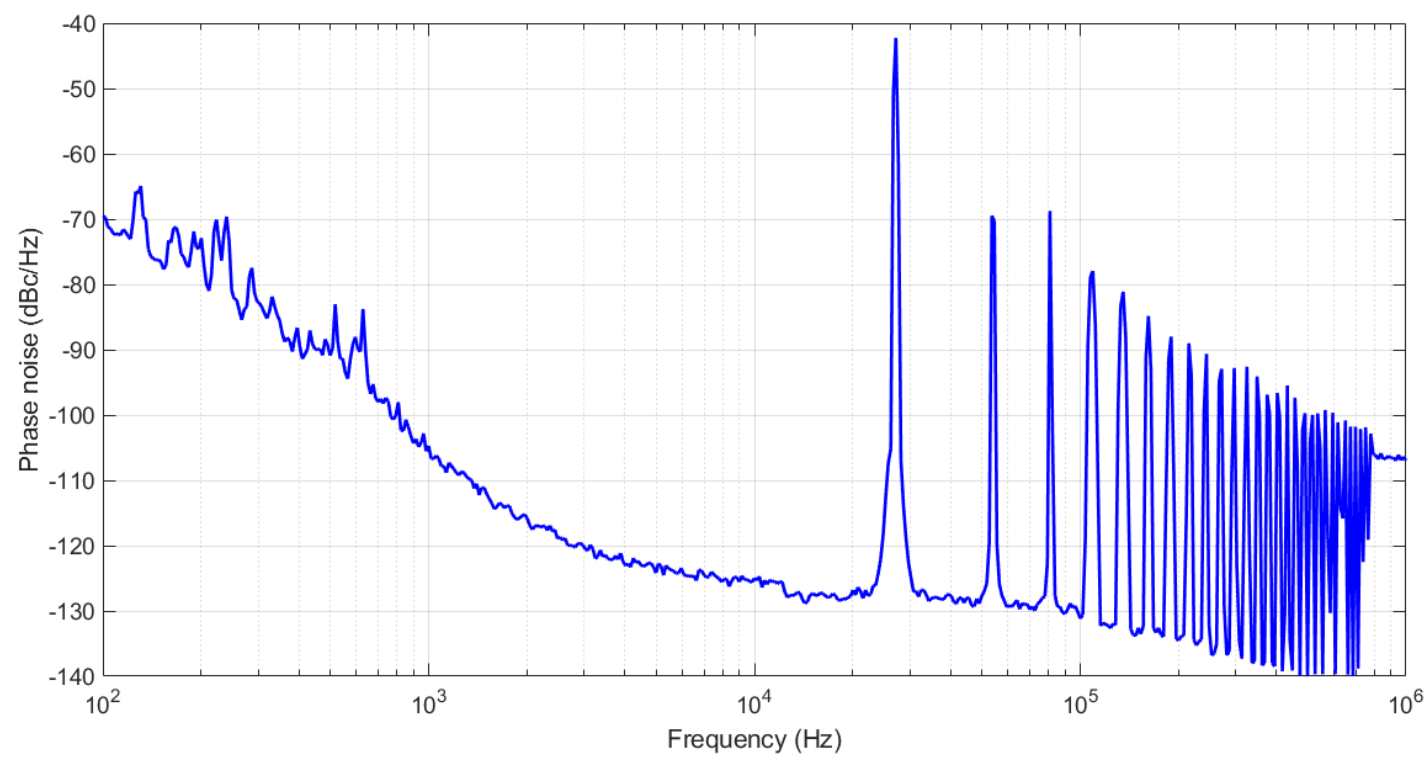

Figure 15. Phase-noise performance of an OEO with a $7.5 \mathrm{~km}$ optical delay line length. 
As can be clearly seen in Figure 15, $-104.7 \mathrm{dBc} / \mathrm{Hz}$ and $-125.0 \mathrm{dBc} / \mathrm{Hz}$ were at $1 \mathrm{kHz}$ and $10 \mathrm{kHz}$ offset from the $10.45 \mathrm{GHz}$ carrier. In this application, the phase noise of the OEO for different optical fiber lengths could be easily measured by adjusting the optical fiber path selector.

\section{Conclusions}

The OEO is a very well-known, high-frequency oscillator for generating low-phase microwave and millimeter wave signals and is used daily in various fields of science, technology and engineering. It has already been shown that an OEO can generate a millimeter wave signal up to the $\mathrm{W}$ band. The OEO has the advantage that the oscillator's phase noise is independent of the operating frequency. However, the OEO might require stabilization for short-term, long-term and multimode operation.

Moreover, the OEO can be developed as a tool/application for various scientific and engineering fields. The wideband OEO was introduced to generate high-frequency signals in the microwave and millimeter wave signal ranges. This enabled the OEO to be tunable up to $\mathrm{GHz}$ and above. In 2017, the manufacture of an OEO on a photonicintegrated chip was added to the literature. The next generation of 5G RAN requires a low-phase-noise oscillator in the millimeter wave range. Thus, we propose to implement the OEO in the central station of the 5G RAN, defined as a LO for frequency up-conversion and down-conversion. This eliminates the requirement for a $\mathrm{LO}$ in each base station, and the clock distribution is also conducted centrally. Moreover, due to its structure, the OEO does not require opto-electronic/electro-optical signal conversion, which can be classified as another advantage. On the other hand, the simple, single-loop OEO cannot meet the requirements of the centralized OEO for 5G RAN. Thus, an injection-locked, millimeter wave OEO with temperature-stabilized components might be employed to exhibit the best performance as a centralized LO for 5G RAN. Furthermore, by combining the optical fiber path selector with the single-loop OEO, we developed an application to measure the FSR, SMSR and phase noise of the OEO for different optical fiber lengths. This application is also practical to test different electrical bandpass filters and find the optimum performance. In the future, we would like to improve the application so that it can be used for testing/verifying/measuring different configurations of OEOs, such as injection-locked, multi-loop, etc. For injection-locked or multi-loop configurations, an additional optical fiber path selector (one or more) is required to find the optimum configuration of the OEO by comparing the SMSR and the phase noise.

In the current state of the art, one of the limitations is designing a stable OEO on the photonic integrated chip. In order to enable mass production of the OEO, which would make it possible to use the OEO in different scientific areas, photonic integration might be useful. However, because of its short delay line length, the photonic integrated OEO has a poor short-term stability. A future study should focus on improving the short-term stability of the integrated OEO. A high Q-factor resonator can be implemented for the photonic integrated chip. If this is achieved, the integrated OEO can easily be combined into the 5G RAN as a centralized local oscillator. On the other hand, the singleloop OEO has its own limitations for long-term stability and multi-mode operation. A variety of different configurations are proposed to reduce the challenges. Multi-loop, injection-locked or coupled OEOs have been used for many years to improve the multimode operating characteristics of the OEO. Moreover, OEOs with a feedback control loop, PLL and temperature stabilization of the optical fiber as well as an electrical bandpass filter are used to reduce the frequency drift of the oscillator signal. Another topic for future research should be the sophisticated design of wideband, tunable, integrated and ordinary OEO operating in the millimeter wave range with acceptable phase noise performance $(<-120 \mathrm{dBc} @ 10 \mathrm{kHz}$ offset from the carrier).

Author Contributions: Conceptualization, methodology, investigation and resources M.A.I., and B.B.; formal analysis and validation B.B.; writing—original draft preparation M.A.I.; writing—review 
and editing M.A.I. and B.B.; supervision, project administration and funding acquisition B.B. Both authors have read and agreed to the published version of the manuscript.

Funding: The work presented in this article was created within the FiWiN5G Innovative Training Network, which has received funding from the European Union's Horizon 2020 Research and Innovation Programme 2014-2018 under the Marie Skłodowska-Curie Action grant agreement No. 642355. The authors also acknowledge the financial support from the Slovenian Research Agency (research core funding No. P2-0246).

Acknowledgments: The authors would like to express their gratitude to the company InLambda BDT d.o.o. for the research equipment and devices. In addition, we would like to thank LPKF d.o.o for filter manufacturing based on laser manufacture.

Conflicts of Interest: The authors declare no conflict of interest.

\section{References}

1. Batagelj, B.; Bogataj, L.; Vidmar, M.; Bostjan, B. Key properties and design issues for an opto-electronic oscillator. In Proceedings of the 2015 17th International Conference on Transparent Optical Networks (ICTON), Budapest, Hungary, 5-9 July 2015; Institute of Electrical and Electronics Engineers (IEEE): New York, NY, USA, 2015; pp. 1-4.

2. Liu, A.; Dai, J.; Xu, K. Stable and Low-Spurs Optoelectronic Oscillators: A Review. Appl. Sci. 2018, 8, 2623. [CrossRef]

3. Yao, X.; Maleki, L. Opto-electronic oscillator and its applications. In International Topical Meeting on Microwave Photonics; MWP 2000 (Cat. No.00EX430); Institute of Electrical and Electronics Engineers (IEEE): New York, NY, USA, $2002 ;$ pp. $265-268$.

4. Tang, J.; Zhu, B.; Zhang, W.; Li, M.; Pan, S.; Yao, J. Hybrid Fourier-domain mode-locked laser for ultra-wideband linearly chirped microwave waveform generation. Nat. Commun. 2020, 11, 1-8. [CrossRef] [PubMed]

5. Sun, Y.; Zhou, K.; Feng, M.; Li, Z.; Zhou, Y.; Sun, Q.; Liu, J.; Zhang, L.; Li, D.; Sun, X.; et al. Room-temperature continuous-wave electrically pumped InGaN/GaN quantum well blue laser diode directly grown on Si. Light. Sci. Appl. 2018, 7, 13. [CrossRef] [PubMed]

6. Corcoran, B.; Tan, M.; Xu, X.; Boes, A.; Wu, J.; Nguyen, T.G.; Chu, S.T.; Little, B.E.; Morandotti, R.; Mitchell, A.; et al. Ultra-dense optical data transmission over standard fibre with a single chip source. Nat. Commun. 2020, 11, 1-7. [CrossRef]

7. Wang, B.; Morgan, J.S.; Sun, K.; Jahanbozorgi, M.; Yang, Z.; Woodson, M.; Estrella, S.; Beling, A.; Yi, X. Towards high-power, high-coherence, integrated photonic mmWave platform with microcavity solitons. Light. Sci. Appl. 2021, 10, 1-10. [CrossRef] [PubMed]

8. Wang, L.; Zhu, N.; Li, W.; Liu, J. A Frequency-Doubling Optoelectronic Oscillator Based on a Dual-Parallel Mach-Zehnder Modulator and a Chirped Fiber Bragg Grating. IEEE Photon. Technol. Lett. 2011, 23, 1688-1690. [CrossRef]

9. Liu, M.; Yin, X.; Ulin-Avila, E.; Geng, B.; Zentgraf, T.; Ju, L.; Wang, F.; Zhang, X. A graphene-based broadband optical modulator. Nat. Cell Biol. 2011, 474, 64-67. [CrossRef]

10. Eliyahu, D.; Seidel, D.; Maleki, L. Phase noise of a high performance OEO and an ultra low noise floor cross-correlation microwave photonic homodyne system. In Proceedings of the 2008 IEEE International Frequency Control Symposium, Honolulu, HI, USA, 18-21 May 2008; IEEE: New York, NY, USA, 2008; pp. 811-814.

11. Levy, E.; Horowitz, M.; Okusaga, O.; Menyuk, C.; Carter, G.; Zhou, W. Study of dual-loop optoelectronic oscillators. In Proceedings of the 2009 IEEE International Frequency Control Symposium Joint with the 22nd European Frequency and Time forum, Besancon, France, 20-24 April 2009; IEEE: New York, NY, USA, 2009; pp. 505-507.

12. Banky, T.; Horvath, B.; Berceli, T. Optimum configuration of multiloop optoelectronic oscillators. J. Optical Soc. of Am. B. 2006, 23, 1371-1380. [CrossRef]

13. Shumakher, E.; Eisenstein, G. A Novel Multiloop Optoelectronic Oscillator. IEEE Photon. Technol. Lett. 2008, 20 , 1881-1883. [CrossRef]

14. Wang, W.; Liu, Y.; Du, X.; Yan, Y.; Yu, C.; Chen, X. A Novel Demodulation Method of Fiber Bragg Grating Sensor Array Based on Wavelength-to-time Mapping and Multiloop Optoelectronic Oscillator. In Optical Fiber Communication Conference (OFC) 2020; The Optical Society: Washington, DC, USA, 2020.

15. Zhu, D.; Du, T.; Pan, S. A Coupled Optoelectronic Oscillator with Performance Improved by Enhanced Spatial Hole Burning in an Erbium-Doped Fiber. J. Lightw. Technol. 2018, 36, 3726-3732. [CrossRef]

16. Yao, X.; Davis, L.; Maleki, L. Coupled optoelectronic oscillators for generating both RF signal and optical pulses. J. Lightw. Technol. 2000, 18, 73-78. [CrossRef]

17. Khayatzadeh, R.; Auroux, V.; Bailly, G.; Fernandez, A.; Llopis, O. Phase noise study based on transfer function in coupled optoelectronic oscillators. In Proceedings of the 2017 International Topical Meeting on Microwave Photonics (MWP), Beijing, China, 23-26 October 2017; Institute of Electrical and Electronics Engineers (IEEE): New York, NY, USA, 2017; pp. 1-4.

18. Lelievre, O.; Crozatier, V.; Baili, G.; Nouchi, P.; Dolfi, D.; Morvan, L.; Goldfarb, F.; Bretenaker, F.; Llopis, O. Low phase noise 10 GHz coupled optoelectronic oscillator. In Proceedings of the 2017 Joint Conference of the European Frequency and Time Forum and IEEE International Frequency Control Symposium (EFTF/IFCS), Besancon, France, 9-13 July 2017; Institute of Electrical and Electronics Engineers (IEEE): New York, NY, USA, 2017; pp. 493-494. 
19. Peng, H.; Du, H.; Guo, R.; Xu, Y.; Zhang, C.; Chen, J.; Chen, Z. Highly Stable and Low Phase Noise 10 GHz RF Signal Generation Based on a Sub-Harmonic Injection Locked Optoelectronic Oscillator. In Proceedings of the 2018 IEEE International Frequency Control Symposium (IFCS), Olympic Valley, CA, USA, 21-24 May 2018; Institute of Electrical and Electronics Engineers (IEEE): New York, NY, USA, 2018; pp. 1-3.

20. Lee, K.; Kim, J.; Choi, W. Injection-Locked Hybrid Optoelectronic Oscillators for Single-Mode Oscillation. IEEE Photon. Technol. Lett. 2008, 20, 1645-1647. [CrossRef]

21. Hudek, K.; Hati, A.; Howe, D.; Nelson, C.; Zhou, W. Further Examination of the Injection-Locked Dual Optoelectronic Oscillator. In Proceedings of the 2007 IEEE International Frequency Control Symposium Joint with the 21st European Frequency and Time Forum, Geneva, Switzerland, 29 May-1 June 2007; Institute of Electrical and Electronics Engineers (IEEE): New York, NY, USA, 2007; pp. 796-800.

22. Lee, K.-H.; Kim, J.-Y.; Choi, W.-Y.; Kamitsuna, H.; Ida, M.; Kurishima, K. Low-Cost Optoelectronic Self-Injection-Locked Oscillators. IEEE Photon. Technol. Lett. 2008, 20, 1151-1153. [CrossRef]

23. Bogataj, L.; Vidmar, M.; Batagelj, B. Opto-Electronic Oscillator with Quality Multiplier. IEEE Trans. Microw. Theory Tech. 2016, 64, 1-6. [CrossRef]

24. Bogataj, L.; Vidmar, M.; Batagelj, B. A Feedback Control Loop for Frequency Stabilization in an Opto-Electronic Oscillator. J. Lightw. Technol. 2014, 32, 3690-3694. [CrossRef]

25. Bagnell, M.; Delfyett, P.J. Optoelectronic oscillator using an ultra-high finesse Fabry-Perot etalon as a photonic filter for low phase noise at high oscillating frequencies. 2013 IEEE Int. Top. Meet. Microw. Photonics 2013, 56-59. [CrossRef]

26. Ozdur, I.; Mandridis, D.; Hoghooghi, N.; Delfyett, P.J. Low Noise Optically Tunable Opto-Electronic Oscillator with Fabry-Perot Etalon. J. Lightw. Technol. 2010, 28, 3100-3106. [CrossRef]

27. Ozdur, I.; Mandridis, D.; Hoghooghi, N.; Delfyett, P.J. Tunable opto-electronic oscillator with an intracavity Fabry-Perot etalon. In Proceedings of the 2010 23rd Annual Meeting of the IEEE Photonics Society, Denver, CO, USA, 20-11 November 2010; IEEE: New York, NY, USA, 2010. [CrossRef]

28. Zhou, W.; Okusaga, O.; Nelson, C.; Howe, D.; Carter, G.M. 10 GHz dual loop opto-electronic oscillator without RF-amplifiers. Integr. Optoelectron. Devices 2008 2008, 6897, 68970Z. [CrossRef]

29. Huang, N.; Li, M.; Deng, Y.; Zhu, N.H. Optical Pulse Generation Based on an Optoelectronic Oscillator with Cascaded Nonlinear Semiconductor Optical Amplifiers. IEEE Photon. J. 2014, 6, 1-8. [CrossRef]

30. Nelson, C.; Hati, A.; Howe, D.; Zhou, W. Microwave Optoelectronic Oscillator with Optical Gain. In Proceedings of the 2007 IEEE International Frequency Control Symposium Joint with the 21st European Frequency and Time Forum, Geneva, Switzerland, 29 May-1 June 2007; Institute of Electrical and Electronics Engineers (IEEE): New York, NY, USA, 2007; pp. $1014-1019$.

31. Nguimdo, R.M.; Saleh, K.P.; Coillet, A.; Lin, G.; Martinenghi, R.; Chembo, Y.K. Phase Noise Performance of Optoelectronic Oscillators Based on Whispering-Gallery Mode Resonators. IEEE J. Quantum Electron. 2015, 51, 1-8. [CrossRef]

32. Volyanskiy, K.; Salzenstein, P.; Tavernier, H.; Pogurmirskiy, M.; Chembo, Y.K.; Larger, L. Compact optoelectronic microwave oscillators using ultra-high Q whispering gallery mode disk-resonators and phase modulation. Opt. Express 2010, 18, 22358-22363. [CrossRef]

33. Savchenkov, A.A.; Ilchenko, V.S.; Byrd, J.; Liang, W.; Eliyahu, D.; Matsko, A.B.; Seidel, D.; Maleki, L. Whispering-gallery mode based opto-electronic oscillators. In Proceedings of the 2010 IEEE International Frequency Control Symposium, Newport Beach, CA, USA, 1-4 June 2010; IEEE: New York, NY, USA, 2010; pp. 554-557. [CrossRef]

34. Merrer, P.-H.; Saleh, K.; Llopis, O.; Berneschi, S.; Cosi, F.; Conti, G.N. Characterization technique of optical whispering gallery mode resonators in the microwave frequency domain for optoelectronic oscillators. Appl. Opt. 2012, 51, 4742-4748. [CrossRef]

35. Saleh, K.; Bouchier, A.; Merrer, P.H.; Llopis, O.; Cibiel, G. Fiber ring resonator based opto-electronic oscillator: Phase noise optimisation and thermal stability study. SPIE-Intl. Soc. Optical. Eng. 2011, 7936, 79360A.

36. Chen, J.; Zheng, Y.; Xue, C.; Zhang, C.; Chen, Y. Filtering effect of SiO2 optical waveguide ring resonator applied to optoelectronic oscillator. Opt. Express 2018, 26, 12638-12647. [CrossRef]

37. Zhou, P.; Pan, S.; Zhu, D.; Guo, R.; Zhang, F.; Zhao, Y. A Compact Optoelectronic Oscillator Based on an Electroabsorption Modulated Laser. IEEE Photon. Technol. Lett. 2013, 26, 86-88. [CrossRef]

38. Tang, J.; Hao, T.; Li, W.; Zhu, N.; Li, M.; Domenech, D.; Banos, R.; Munoz, P.; Capmany, J. An integrated optoelectronic oscillator. In Proceedings of the 2017 International Topical Meeting on Microwave Photonics (MWP), Beijing, China, 23-26 October 2017; IEEE: New York, NY, USA, 2017; pp. 1-4. [CrossRef]

39. Hao, T.; Liu, Y.; Tang, J.; Cen, Q.; Li, W.; Zhu, N.; Dai, Y.; Capmany, J.; Yao, J.; Li, M. Recent advances in optoelectronic oscillators. Adv. Photon. 2020, 2, 044001. [CrossRef]

40. Banerjee, A.; De Britto, L.A.D.; Pacheco, G.M. A Theoretical and Experimental Study of Injection-Locking and Injection-Pulling for Optoelectronic Oscillators Under Radio Frequency Signal Injection. J. Lightw. Technol. 2019, 38, 1210-1220. [CrossRef]

41. Banerjee, A.; De Britto, L.A.D.; Pacheco, G.M. Analysis of Injection Locking and Pulling in Single-Loop Optoelectronic Oscillator. In IEEE Transactions on Microwave Theory and Techniques; IEEE: New York, NY, USA, 2019; Volume 67, pp. 2087-2094. [CrossRef]

42. Banerjee, A.; Sarkar, J.; De Britto, L.A.D.; Pacheco, G.M.; Das, N.R. On the Transient Behavior of Single-Loop Optoelectronic Oscillators Under RF Injection-Locking. IEEE J. Quantum Electron. 2020, 56, 1-13. [CrossRef]

43. Banerjee, A.; De Britto, L.A.D.; Pacheco, G.M. Study of injection-locking and injection-pulling in injection-locked optoelectronic oscillator under radio frequency signal injection. Opt. Eng. 2019, 58, 58. [CrossRef] 
44. Banerjee, A.; De Britto, L.A.D.; Pacheco, G.M. Analysis of phase noise in self-injection-locked optoelectronic oscillator. Optik 2020, 223, 165475. [CrossRef]

45. Hasanuzzaman, G.K.M.; Iezekiel, S.; Kanno, A. W-Band Optoelectronic Oscillator. IEEE Photon. Technol. Lett. 2020, 32, 771-774. [CrossRef]

46. Hao, T.; Cen, Q.; Guan, S.; Li, W.; Dai, Y.; Zhu, N.; Li, M. Optoelectronic parametric oscillator. Lightw. Sci. Appl. 2020, 9, 9. [CrossRef]

47. Hasanuzzaman, G.; Shams, H.; Renaud, C.C.; Mitchell, J.; Iezekiel, S. Photonic THz Generation using Optoelectronic Oscillatordriven Optical Frequency Comb Generator. In Proceedings of the 2018 International Topical Meeting on Microwave Photonics (MWP), Toulouse, France, 22-25 October 2018; Institute of Electrical and Electronics Engineers (IEEE): New York, NY, USA, 2018; pp. 1-4.

48. Hasanuzzaman, G.K.M.; Shams, H.; Renaud, C.C.; Mitchell, J.; Seeds, A.J.; Iezekiel, S. Tunable THz Signal Generation and Radio-Over-Fiber Link Based on an Optoelectronic Oscillator-Driven Optical Frequency Comb. J. Lightw. Technol. 2020, 38, 5240-5247. [CrossRef]

49. Hasanuzzaman, G.K.M.; Shams, H.; Renaud, C.C.; Mitchell, J.; Seeds, A.J.; Iezekiel, S. Cascaded Microwave Photonic Filters for Side Mode Suppression in a Tunable Optoelectronic Oscillator applied to THz Signal Generation \& Transmission. IEEE Photon. J. 2021, 13, 1-11. [CrossRef]

50. Ilgaz, M.A.; Batagelj, B. Opto-electronic oscillator in the $\mathrm{mm}-\mathrm{W}$ range for $5 \mathrm{G}$ wireless and mobile networks: Design challenges and possible solutions. In Proceedings of the 2017 International Conference on Optical Network Design and Modeling (ONDM), Budapest, Hungary, 15-18 May 2017; IEEE: New York, NY, USA, 2017.

51. Ilgaz, M.A.; Batagelj, B. Application of an Opto-Electronic Oscillator in 5G Mobile and Wireless Networks with a Low Frequency Drift, a High Side-Modes-Suppression Ratio and without a Power Penalty due to Chromatic Dispersion. In Proceedings of the 2018 European Conference on Networks and Communications (EuCNC), Ljubljana, Slovenia, 18-21 June 2018; Institute of Electrical and Electronics Engineers (IEEE): New York, NY, USA, 2018; pp. 388-392.

52. Ilgaz, M.A.; Batagelj, B. Using Tunable Dispersion-Compensated Modules to Overcome the Power Penalty of a Millimeter-Wave Opto-Electronic Oscillator Signal that is Distributed via a Passive Optical Network for 5G Networks. In Proceedings of the 2018 11th International Symposium on Communication Systems, Networks \& Digital Signal Processing (CSNDSP), Budapest, Hungary, 18-20 July 2018; IEEE: New York, NY, USA, 2018; pp. 1-6. [CrossRef]

53. Ilgaz, M.A.; Batagelj, B. Measurement of the Free Spectral Range and the Side-Modes Suppression Ratio of a 9.3-GHz Single-Loop Opto-Electronic Oscillator by Fiber Path Selector. In Proceedings of the 2018 26th Telecommunications Forum (TELFOR), Belgrade, Serbia, 20-21 November 2018; Institute of Electrical and Electronics Engineers (IEEE): New York, NY, USA, 2018 ; pp. 1-4.

54. Okusaga, O.; Pritchett, J.; Sorenson, R.; Zhou, W.; Berman, M.; Cahill, J.; Carter, G.M.; Menyuk, C.R. The OEO as an acoustic sensor. In Proceedings of the 2013 Joint European Frequency and Time Forum \& International Frequency Control Symposium (EFTF/IFC), Prague, Czech Republic, 21-25 July 2013; Institute of Electrical and Electronics Engineers (IEEE): New York, NY, USA, 2013; pp. 66-68.

55. Shao, Y.; Han, X.; Ye, Q.; Zhu, B.; Dai, Y.; Wang, C.; Zhao, M. Low-Power RF Signal Detection Using a High-Gain Tunable OEO Based on Equivalent Phase Modulation. J. Lightw. Technol. 2019, 37, 5370-5379. [CrossRef]

56. Zhang, L.; Poddar, A.K.; Rohde, U.L.; Daryoush, A S. Self-injection locked phase-locked loop OEO. In IEEE MTT-S International Microwave and RF Conference; IEEE: New York, NY, USA, 2013; pp. 1-4.

57. Peng, H.; Liu, N.; Li, Y.; Xie, X.; Chen, Z. Low Phase Noise and Highly Stable Optoelectronic Oscillator by Using FrequencyMultiplying Phase Locked Loop. In Proceedings of the 2020 Joint Conference of the IEEE International Frequency Control Symposium and International Symposium on Applications of Ferroelectrics (IFCS-ISAF), Keystone, CO, USA, 19-23 July 2020; Institute of Electrical and Electronics Engineers (IEEE): New York, NY, USA, 2020; pp. 1-2.

58. Zhang, L.; Poddar, A.K.; Rohde, U.L.; Daryoush, A.S. Comparison of Optical Self-Phase Locked Loop Techniques for Frequency Stabilization of Oscillators. IEEE Photon. J. 2014, 6, 1-15. [CrossRef]

59. Zhang, J.; Yao, J. Parity-time-symmetric optoelectronic oscillator. Sci. Adv. 2018, 4, eaar6782. [CrossRef]

60. Liu, Y.; Hao, T.; Li, W.; Capmany, J.; Zhu, N.; Li, M. Observation of parity-time symmetry in microwave photonics. Light. Sci. Appl. 2018, 7, 1-9. [CrossRef] [PubMed]

61. Do, P.T.; Alonso-Ramos, C.; Le Roux, X.; Le Doux, I.; Journet, B.; Cassan, E. Wideband tunable microwave signal generation in a silicon-micro-ring-based optoelectronic oscillator. Sci. Rep. 2020, 10, 1-9. [CrossRef] [PubMed]

62. Zhou, P.; Zhang, F.; Pan, S. Generation of Linear Frequency-Modulated Waveforms by a Frequency-Sweeping Optoelectronic Oscillator. J. Lightw. Technol. 2018, 36, 3927-3934. [CrossRef]

63. Hao, T.; Tang, J.; Domenech, D.; Li, W.; Zhu, N.H.; Capmany, J.; Li, M. Toward Monolithic Integration of OEOs: From Systems to Chips. J. Lightw. Technol. 2018, 36, 4565-4582. [CrossRef]

64. Huang, L.; Deng, L.; Fu, S.; Tang, M.; Cheng, M.; Zhang, M.; Liu, D. Stable and Compact Dual-Loop Optoelectronic Oscillator Using Self-Polarization-Stabilization Technique and Multicore Fiber. J. Lightw. Technol. 2018, 36, 5196-5202. [CrossRef]

65. Li, M.; Li, L.; Zhang, J.; Yao, J. Dual-Loop and Parity-Time-Symmetric Optoelectronic Oscillator with Strong Sidemode Suppression. In Proceedings of the 2020 International Topical Meeting on Microwave Photonics (MWP), Matsue, Japan, 24-26 November 2020; IEEE: New York, NY, USA, 2020. 
66. Zhou, W.; Blasche, G. Injection-locked dual opto-electronic oscillator with ultra-low phase noise and ultra-low spurious level. IEEE Trans. Microw. Theory Tech. 2005, 53, 929-933. [CrossRef]

67. Xu, W.; Yang, C.; Wang, Z.; Zhao, W. Tunable Low-Spurious Heterodyne-Dual-Injection-Locked Optoelectronic Oscillator. In Proceedings of the 2019 International Topical Meeting on Microwave Photonics (MWP), Ottawa, ON, Canada, 7-10 October 2019; Institute of Electrical and Electronics Engineers (IEEE): New York, NY, USA, 2019; pp. 1-3.

68. Peng, H.; Guo, R.; Du, H.; Xu, Y.; Zhang, C.; Chen, J.; Chen, Z. Low Phase Noise 20 GHz Microwave Frequency Divider Based on a Super-Harmonic Injection Locked Optoelectronic Oscillator. In Proceedings of the 2018 IEEE International Frequency Control Symposium (IFCS), Olympic Valley, CA, USA, 21-24 May 2018; Institute of Electrical and Electronics Engineers (IEEE): New York, NY, USA, 2018; pp. 1-3.

69. Shi, M.; Yi, L.; Hu, W. High-Resolution Brillouin Optoelectronic Oscillator Using High-Order Sideband Injection-Locking. IEEE Photon. Technol. Lett. 2019, 31, 513-516. [CrossRef]

70. Yao, X.S.; Maleki, L. Dual microwave and optical oscillator. Opt. Lett. 1997, 22, 1867-1869. [CrossRef] [PubMed]

71. Ly, A.; Auroux, V.; Khayatzadeh, R.; Gutierrez, N.; Fernandez, A.; Llopis, O. Highly Spectrally Pure 90-GHz Signal Synthesis Using a Coupled Optoelectronic Oscillator. IEEE Photon. Technol. Lett. 2018, 30, 1313-1316. [CrossRef]

72. Zhu, D.; Wei, Z.; Du, T.; Pan, S. A coupled optoelectronic oscillator based on enhanced spatial hole burning effect. In Proceedings of the 2016 IEEE International Topical Meeting on Microwave Photonics (MWP), Long Beach, CA, USA, 31 October-3 November 2016.

73. Liu, A.; Liu, J.; Dai, J.; Dai, Y.; Yin, F.; Li, J.; Zhou, Y.; Zhang, T.; Xu, K. Spurious Suppression in Millimeter-Wave OEO With a High- $Q$ Optoelectronic Filter. IEEE Photon. Technol. Lett. 2017, 29, 1671-1674. [CrossRef]

74. Yang, Y.-D.; Liao, M.-L.; Han, J.-Y.; Weng, H.-Z.; Xiao, J.-L.; Huang, Y.-Z. Narrow-Linewidth Microwave Generation by Optoelectronic Oscillators with AlGaInAs/InP Microcavity Lasers. J. Lightw. Technol. 2018, 36, 4379-4385. [CrossRef]

75. Eliyahu, D.; Sariri, K.; Kamran, A.; Tokhmakhian, M. Improving short and long term frequency stability of the opto-electronic oscillator. In Proceedings of the 2002 IEEE International Frequency Control Symposium and PDA Exhibition, Cat. No.02CH37234. New Orleans, LA, USA, 29-31 May 2002; Institute of Electrical and Electronics Engineers (IEEE): New York, NY, USA, 2003; pp. 580-583.

76. Bogataj, L.; Vidmar, M.; Batagelj, B. Improving the Side-mode Suppression Ratio and Reducing the Frequency Drift in an Opto-Electronic Oscillator With a Feedback Control Loop and Additional Phase Modulation. J. Lightw. Technol. 2015, 34, 885-890. [CrossRef]

77. Bogataj, L.; Tratnik, J.; Batagelj, B.; Dragonja, U. A highly stable OEO using a multi-purpose optical-delay stabilization system. In Proceedings of the 2017 Joint Conference of the European Frequency and Time Forum and IEEE International Frequency Control Symposium (EFTF/IFCS), Besancon, France, 9-13 July 2017; Institute of Electrical and Electronics Engineers (IEEE): New York, NY, USA, 2017; pp. 486-488.

78. Zhang, Y.; Hou, D.; Zhao, J. Long-Term Frequency Stabilization of an Optoelectronic Oscillator Using Phase-Locked Loop. J. Lightw. Technol. 2014, 32, 2408-2414. [CrossRef]

79. Tseng, W.-H.; Feng, K.-M. Enhancing long-term stability of the optoelectronic oscillator with a probe-injected fiber delay monitoring mechanism. Opt. Express 2012, 20, 1597-1607. [CrossRef] [PubMed]

80. Li, W.; Yao, J. An Optically Tunable Optoelectronic Oscillator. J. Lightw. Technol. 2010, 28, 2640-2645. [CrossRef]

81. Wo, J.; Wang, A.; Zhang, J.; Zhang, D.; Wang, Y.; Du, P.; Cong, W.; Yu, L. Wideband tunable microwave generation using a dispersion compensated optoelectronic oscillator. In Proceedings of the 2017 Opto-Electronics and Communications Conference (OECC) and Photonics Global Conference (PGC), Singapore, 31 July-4 August 2017; Institute of Electrical and Electronics Engineers (IEEE): New York, NY, USA, 2017; pp. 1-2.

82. Liu, S.; Lv, K.; Fu, J.; Wu, L.; Pan, W.; Pana, S. Wideband Microwave Frequency Division Based on an Optoelectronic Oscillator. IEEE Photon. Technol. Lett. 2019, 31, 389-392. [CrossRef]

83. Yu, Y.; Tang, H.; Xiao, X.; Yu, Y.; Zhang, X. Ultra-High-Q Silicon Microring Resonator Based Optoelectronic Oscillator with Stabilized Frequency. In Proceedings of the 2019 International Topical Meeting on Microwave Photonics (MWP), Ottawa, ON, Canada, 7-10 October 2019; Institute of Electrical and Electronics Engineers (IEEE): New York, NY, USA, 2019; pp. 1-3.

84. Tang, J.; Hao, T.; Li, W.; Domenech, D.; Baños, R.; Muñoz, P.; Zhu, N.; Capmany, J.; Li, M. Integrated optoelectronic oscillator. Opt. Express 2018, 26, 12257-12265. [CrossRef] [PubMed]

85. Zhang, W.; Yao, J. Silicon Photonic Integrated Optoelectronic Oscillator for Frequency-Tunable Microwave Generation. J. Lightw. Technol. 2018, 36, 4655-4663. [CrossRef]

86. Xuan, Z.; Du, L.; Aflatouni, F. Frequency locking of semiconductor lasers to RF oscillators using hybrid-integrated opto-electronic oscillators with dispersive delay lines. Opt. Express 2019, 27, 10729-10737. [CrossRef] [PubMed]

87. Kim, Y.; Sun, F.; Wang, Y.; Qi, Y.; Lee, J.; Kim, Y.; Oh, J.; Ji, H.; Yeo, J.; Choi, S.; et al. New Radio (NR) and its Evolution toward 5G-Advanced. IEEE Wirel. Commun. 2019, 26, 2-7. [CrossRef]

88. Patzold, M. It's time to go big with 5G [mobile radio]. IEEE Veh. Technol. Mag. 2018, 13, 4-10. [CrossRef]

89. Marozsak, T.; Berceli, T.; Jaro, G.; Zolomy, A.; Hilt, A.; Mihály, S.; Udvary, É.; Varga, Z. A new optical distribution approach for millimeter wave radio. In International Topical Meeting on Microwave Photonics. Technical Digest (including High Speed Photonics Components Workshop); Cat. No.98EX181; Institute of Electrical and Electronics Engineers (IEEE): New York, NY, USA, 2002; pp. 63-66. 
90. Qasim, A.; Mehmood, T.; Ali, U.; Khan, Q.U.; Ghafoor, S. Dual-ring radio over fiber system with centralized light sources and local oscillator for millimeter-wave transmission. In Proceedings of the 2017 International Multi-topic Conference (INMIC), Lahore, Pakistan, 24-26 November 2017; Institute of Electrical and Electronics Engineers (IEEE): New York, NY, USA, 2017; pp. 1-5.

91. Ye, C.; Zhang, L.; Zhu, M.; Yu, J.; He, S.; Chang, G.-K. A Bidirectional 60-GHz Wireless-Over-Fiber Transport System with Centralized Local Oscillator Service Delivered to Mobile Terminals and Base Stations. IEEE Photon. Technol. Lett. 2012, 24, 1984-1987. [CrossRef]

92. Shan, C.; Galayko, D.; Anceau, F.; Zianbetov, E. A reconfigurable distributed architecture for clock generation in large many-core SoC. In Proceedings of the 2014 9th International Symposium on Reconfigurable and Communication-Centric Systems-on-Chip (ReCoSoC), Montpellier, France, 26-28 May 2014; Institute of Electrical and Electronics Engineers (IEEE): New York, NY, USA, 2014; pp. 1-8.

93. Ilgaz, M.A.; Baliz, K.V.; Batagelj, B. A Flexible Approach to Combating Chromatic Dispersion in a Centralized 5G Network. Opto. Electron. Rev. 2020, 28, 35-42. [CrossRef]

94. Khan, M.A.; Ali, F.; Irfan, M.; Muhammad, F.; Althobiani, F.; Ali, A.; Khan, S.; Rahman, S.; Perun, G.; Glowacz, A. Mitigation of Phase Noise and Nonlinearities for High Capacity Radio-over-Fiber Links. Electronics 2021, 10, 345. [CrossRef]

95. Paredes-Páliz, D.F.; Royo, G.; Aznar, F.; Aldea, C.; Celma, S. Radio over Fiber: An Alternative Broadband Network Technology for IoT. Electronics 2020, 9, 1785. [CrossRef]

96. Rahman, S.; Ali, F.; Smagor, A.; Muhammad, F.; Habib, U.; Glowacz, A.; Ahmad, S.; Irfan, M.; Smalcerz, A.; Kula, A.; et al. Mitigation of Nonlinear Distortions for a $100 \mathrm{~Gb} / \mathrm{s}$ Radio-Over-Fiber-Based WDM Network. Electronics 2020, 9, 1796. [CrossRef]

97. Ogawa, K.; Tomiyama, K.; Tan, Y.T.; Doan, M.T.; Bin, Y.M.; Kwong, D.-L.; Yamada, S.; Cole, J.B.; Katayama, Y.; Mizuta, H.; et al. Broadband variable chromatic dispersion in photonic-band electro-optic waveguide. In Proceedings of the 2006 Optical Fiber Communication Conference and the National Fiber Optic Engineers Conference, Anaheim, CA, USA, 5-10 March 2006; Institute of Electrical and Electronics Engineers (IEEE): New York, NY, USA, 2006; p. 3.

98. Hosseini, S.E.; Banai, A. Analytical Prediction of the Main Oscillation Power and Spurious Levels in Optoelectronic Oscillators. J. Lightw. Technol. 2013, 32, 978-985. [CrossRef]

99. Yao, X.S.; Maleki, L. Optoelectronic microwave oscillator. J. Opt. Soc. Am. B 1996, 13, 1725-1735. [CrossRef]

100. Ilgaz, M.A.; Lavric, A.; Odedeyi, T.; Darwazeh, I.; Batagelj, B. Adjustable testing setup for a single-loop optoelectronic oscillator with an electrical bandpass filter. Turk. J. Electr. Eng. Comput. Sci. 2020, 28, 1293-1302. [CrossRef] 